Article

\title{
Dextran-Thyme Magnesium-Doped Hydroxyapatite Composite Antimicrobial Coatings
}

\author{
Simona Liliana Iconaru ${ }^{1}$, Mihai Valentin Predoi ${ }^{2, *} \mathbb{0}$, Mikael Motelica-Heino ${ }^{3}$, Daniela Predoi ${ }^{1}$, \\ Nicolas Buton ${ }^{4}$, Christelle Megier ${ }^{4}$ and George E. Stan ${ }^{1, *}$ \\ 1 National Institute of Materials Physics, 405A Atomistilor Street, 077125 Magurele, Romania; \\ simonaiconaru@gmail.com (S.L.I.); dpredoi@gmail.com (D.P.) \\ 2 University Politehnica of Bucharest, BN 002, 313 Splaiul Independentei, Sector 6, 060042 Bucharest, Romania \\ 3 ISTO, UMR 7327 CNRS Université d'Orléans, 1A rue de la Férollerie, 45071 Orléans CEDEX 2, France; \\ mikael.motelica@univ-orleans.fr \\ 4 HORIBA Jobin Yvon S.A.S., 6-18, Rue du Canal, 91165 Longjumeau CEDEX, France; \\ nicolas.buton@horiba.com (N.B.); christelle.megier@horiba.com (C.M.) \\ * Correspondence: predoi@gmail.com (M.V.P.); george_stan@infim.ro (G.E.S.)
}

Received: 30 November 2019; Accepted: 7 January 2020; Published: 9 January 2020

\begin{abstract}
The dextran-thyme magnesium-doped hydroxyapatite (10MgHAp-Dex-thyme) composite layers were prepared by a dip-coating procedure from stable suspensions and further analyzed for the first time. Different characterization techniques were employed to explore the physical-chemical features of the 10MgHAp-Dex-thyme suspensions and derived coatings. Information regarding the 10MgHAp-Dex-thyme suspensions was extracted on the basis of dynamic light scattering, zeta potential, and ultrasound measurements. The crystalline quality of the biocomposite powders-resulting after the centrifugation of suspensions-and the layers deposited on glass was assessed by X-ray diffraction in symmetric and grazing incidence geometries, respectively. The chemical structure and presence of functional groups were evaluated for both powder and coating by Fourier transform infrared spectroscopy in attenuated total reflectance mode. The extent of the antimicrobial effect range of the biocomposite suspensions and coatings was tested against different Gram-positive and Gram-negative bacteria (Staphylococcus aureus, Enterococcus faecalis, Escherichia coli, and Pseudomonas aeruginosa) and fungus (Candida albicans) strains with promising results.
\end{abstract}

Keywords: antimicrobials; magnesium doping; hydroxyapatite; dextran; thyme oil; composite coatings; solution ultrasound measurements

\section{Introduction}

In the last decades, the general increase of life-expectancy combined with a higher incidence of bone disorders has led to a growing demand for bone medical devices (e.g., bone graft substitutes; implants with faster osseointegration and long-lasting performance), capable to replace, reinforce, or treat affected hard tissues [1-7]. After blood, the bone became the second most frequently transplanted tissue/substance in the human body [8]. In this context, the development of novel materials for such biomedical applications has attracted considerable attention around the globe [1-7]. Most often, the materials used for bone replacement or tissue engineering are based on bioactive substances, having similar features with respect to the human hard tissue [5-7]. Amongst the bioactive materials, due to its remarkable biocompatible and osteoconductive properties and chemical similarity with the major bone mineral phase, hydroxyapatite $\left[\mathrm{HAp}, \mathrm{Ca}_{10}\left(\mathrm{PO}_{4}\right)_{6}(\mathrm{OH})_{2}\right]$ is currently used for numerous biomedical applications in a wide range of healthcare domains, such as orthopedics, dentistry, pharmaceutics, cosmetics, as well as in the food industry [6,7,9-12]. The HAp has been reported to boost the 
proliferation of human cells and to stimulate the osteointegration process $[13,14]$. Presently, HAp is clinically used in the form of bone graft substitutes or thick implant coatings (fabricated by plasma spray). However, standalone, this material does not possess the ability to inhibit bone resorption and, markedly important, to endow antimicrobial properties. This needs to be emphasized as the bacterial-associated infections are currently a major cause of bone scaffolds and dental implants failure [15-18]. Consequently, numerous studies have been conducted for the development of a synthetic HAp with enhanced properties that could lead to an improvement of mechanical properties, osteointegration, implantation efficiency, and prevention of post-operatory infections [1,2]. Nowadays, there is a considerable number of microbial strains, which have developed resistance to conventional antimicrobial agents and are responsible for severe infections $[1,13,14,19]$. The HAp research is majorly oriented towards the enhancement of its biofunctionality by doping it with various types of metal ions (e.g., $\mathrm{Ag}^{+}, \mathrm{Sr}^{2+}, \mathrm{Zn}^{2+}, \mathrm{Cu}^{2+}, \mathrm{Mn}^{2+}, \mathrm{Na}^{+}, \mathrm{Ce}^{3+}, \mathrm{Eu}^{3+}, \mathrm{Sm}^{3+}$ ), which can induce morphological and structural (e.g., crystallinity, lattice parameters) modifications with effects on the dissolution kinetics of HAp and the release rate of therapeutic ions [1,2]. Such type of ionic substitutions could contribute to the development of novel materials with outstanding properties. Amongst the metal ions, which could be accommodated by the HAp structure, the most studied ones have been $\mathrm{Ag}^{+}, \mathrm{Sr}^{2+}, \mathrm{Zn}^{2+}$, and $\mathrm{Cu}^{2+}$, yielding certain benefits with respect to the biological (e.g., osteogenic and angiogenic capacity, antimicrobial effect) and mechanical properties of HAp [1,2,7-14]. Moreover, due to the emergence of drug-resistant bacterial strains, the development of novel antimicrobial agents has also shifted focus towards the use of essential oils (EOs) with long-lasting curative properties, obtained from abundant plants [20-24]. EOs are naturally synthesized substances, and most of them are generally recognized as safe (GRAS) when their dosage is similar to the one found in foods [21]. The list of EOs that have been approved by the Food and Drug Administration (FDA) for the use in foods and drinks includes the essential oil derived from Thymus vulgaris L. [25]. The antimicrobial properties of thyme EO have been previously reported against a pathogenic and/or spoilage food-related bacterium [26,27], as well as against common bacterial strains, such as Staphylococcus aureus and Listeria monocytogenes [23]. Nonetheless, there are several emerging cations with both antimicrobial properties and important roles in the enhancement of the biological interactions of HAp with the surrounding tissues, amid which $\mathrm{Mg}^{2+}$ comes into prominence [28-30]. Magnesium is one of the most important essential trace elements, being involved in the development of bones and connective tissues and possessing osteogenic and angiogenic stimulating properties, demonstrated both in vitro and in vivo [31-35]. Moreover, it has been reported that this specific trace element plays a significant role in the bone calcification process, influencing the osteoblast and osteoclast activities [32]. However, some studies also evidenced that the addition of $\mathrm{Mg}$ could lead to an inhibitory effect of HAp nucleation, alteration of HAp structure, and decomposition or segregation of secondary phases at high dopant concentrations [33,36].

In a previous study [30], the authors explored the stability of Mg-doped HAp $\left(\mathrm{Ca}_{10-\mathrm{x}} \mathrm{Mg}_{\mathrm{x}}\left(\mathrm{PO}_{4}\right)_{6}(\mathrm{OH})_{2}, \mathrm{x}_{\mathrm{Mg}}=0.1\right)$ suspensions, which were characterized by remarkable biocompatibility and antimicrobial efficacy against Pseudomonas aeruginosa, S. aureus, and Candida albicans microbial strains. The coupling of $\mathrm{Mg}$ doping and thyme $\mathrm{EO}$ antibacterial agents within a nano-HAp milieu might yield improved biofunctional properties. The development of such novel materials with stable properties could be created by using biopolymers as matrices. Polymers from the polysaccharide family (especially dextran) are the most commonly used in the synthesis of stable composite materials.

In order to achieve durable biocompatible antimicrobial coatings, the suspensions should have good stability. Thereby, in this current study, we aimed to increase the stability of Mg-doped HAp nanoparticle suspensions in conjunction with a dextran and thyme solution. Subsequently, coatings were fabricated, and their morphological and structural features were scrutinized. Finally, the antimicrobial properties of the coatings against S. aureus, Enterococcus faecalis, Escherichia coli, P. aeruginosa, and C. albicans bacteria and fungus strains were evaluated. 


\section{Materials and Methods}

\subsection{Materials}

The synthesis of $\mathrm{Ca}_{10-\mathrm{x}} \mathrm{Mg}_{\mathrm{x}}\left(\mathrm{PO}_{4}\right)_{6}(\mathrm{OH})_{2}$ in dextran-thyme solution was performed using ammonium hydrogen phosphate, $\left(\mathrm{NH}_{4}\right)_{2} \mathrm{HPO}_{4}$ (Sigma Aldrich, St. Louis, MO, USA, purity $\geq$ $99 \%$ ), calcium nitrate tetrahydrate, $\mathrm{Ca}\left(\mathrm{NO}_{3}\right)_{2} \cdot{ }_{4} \mathrm{H}_{2} \mathrm{O}$ (Sigma Aldrich, St. Louis, $\mathrm{MO}$, USA, purity $\geq 99 \%$ ), magnesium nitrate hexahydrate, $\mathrm{Mg}\left(\mathrm{NO}_{3}\right)_{2} \cdot 6 \mathrm{H}_{2} \mathrm{O}$ (Alpha Aesar, Germany, purity $99.97 \%$ ), ammonium

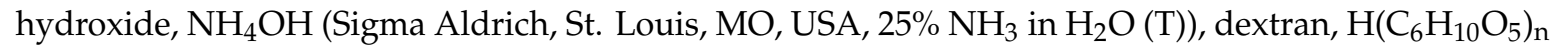
(Sigma Aldrich, St. Louis, MO, USA, Mr 40,000), thyme essential oil, ethanol absolute, $\mathrm{C}_{2} \mathrm{H}_{6} \mathrm{O}$ (Sigma Aldrich, St. Louis, MO, USA, purity $\geq 99.8 \%$ ), and double-distilled water.

\subsection{Dextran-Thyme Coated Magnesium-Doped Hydroxyapatite (10MgHAp-Dex-thyme) Nanoparticle Suspensions}

The Mg-doped HAp nanoparticles in dextran-thyme solution were prepared by an adapted chemical co-precipitation method, presented elsewhere $[37,38]$. The synthesis of $\mathrm{Ca}_{10-\mathrm{x}} \mathrm{Mg}_{\mathrm{x}}\left(\mathrm{PO}_{4}\right)_{6}(\mathrm{OH})_{2}$ with $\mathrm{x}_{\mathrm{Mg}}=0.1$ was performed at room temperature $(\mathrm{RT})$. The $(\mathrm{Ca}+\mathrm{Mg}) / \mathrm{P}$ molar ratio was set to the stoichiometric value of 1.67 [39,40]. The solution, obtained by dissolving $\mathrm{Ca}\left(\mathrm{NO}_{3}\right)_{2} \cdot 4 \mathrm{H}_{2} \mathrm{O}$ and $\mathrm{Mg}\left(\mathrm{NO}_{3}\right)_{2} \cdot 6 \mathrm{H}_{2} \mathrm{O}$ in a beaker, was added drop-by-drop into a solution of $\left(\mathrm{NH}_{4}\right)_{2} \cdot \mathrm{HPO}_{4}$. Throughout the synthesis process, the $\mathrm{pH}$ of the solution was kept constant at a value of 11 by adding $\mathrm{NH}_{4} \mathrm{OH}$. After stirring, the solution was centrifuged and redispersed in deionized water. This operation was repeated 5 times. After the last centrifugation, the resulting precipitate was redispersed in a dextran solution (10\%) and thyme essential oil $(1 \mathrm{~mL}$ per $100 \mathrm{~mL}$ dextran solution). The resulting solution was stirred for $6 \mathrm{~h}$ at $80^{\circ} \mathrm{C}$, followed by stirring for $24 \mathrm{~h}$ at 40 ${ }^{\circ} \mathrm{C}$. Then, the solution was mixed by ultrasonication for $6 \mathrm{~h}$. The final solution, hereinafter referred to as $10 \mathrm{MgHAp}$-Dex-thyme, was used to obtain the coatings.

\subsection{Deposition of $10 M g H A p$-Dex-Thyme Coatings}

The 10MgHAp-Dex-thyme layers were prepared by a dip-coating procedure, previously described in [41]. Mirror polished optically transparent microscopy glass slides were used as substrates. Prior deposition, the substrates were degreased with acetone and then washed with deionized water. Then, the $10 \mathrm{MgHAp}$-Dex-thyme layers were laid on substrates. The deposited layers were initially dried at $80^{\circ} \mathrm{C}$ for $4 \mathrm{~h}$, and then heat-treated in the air at $500{ }^{\circ} \mathrm{C}$ for $30 \mathrm{~min}$. After the thermal-treatment, the deposited layer was cooled-down to ambient temperature with a rate of $5^{\circ} \mathrm{C} / \mathrm{min}$.

\subsection{Physico-Chemical and Mechanical Characterization Methods}

(a) The zeta-potential (ZP) measurements were carried out using a Horiba-Jobin Yvon SZ-100 Nanoparticle Analyzer (Horiba Ltd., Kyoto, Japan) at $25 \pm 1{ }^{\circ} \mathrm{C}$. The wavelength at which the 2 $\mathrm{He}-\mathrm{Ne}$ laser beams were operated was $532 \mathrm{~nm}$. The samples were measured in triplicate, and the results were averaged. The zeta-potential was performed on the diluted sample.

(b) The ultrasound measurements were performed on concentrated solutions obtained from the preparation process. The ultrasound pulses were sent by the analyzed suspension [38]. Digital signals from the oscilloscope were recorded at a very precise interval of $5 \mathrm{~s}$. For good signal processing, a comparison with the properties of double-distilled water (the most stable suspension) was performed. Double-distilled water was considered as reference fluid, analyzed under the same experimental conditions.

(c) The morphology of the 10MgHAp-Dex-thyme suspension particles and derived-coatings was explored by scanning electron microscopy (SEM) using a Hitachi S4500 equipment (Hitachi, Tokyo, Japan).

(d) The qualitative (elemental distribution maps) and quantitative composition of samples were analyzed by energy-dispersive X-ray spectroscopy (EDS) with an EDAX (Ametek EDAX Inc., 
Mahwah, NJ, USA). The EDS quantitative analyses were performed on four randomly SEM selected $\left(\sim 250 \times 250 \mu \mathrm{m}^{2}\right)$ surface regions. The EDS data were calibrated using a NIST $2910 \mathrm{~b}$ hydroxyapatite standard reference material. The data were presented as mean \pm standard deviation (SD).

(e) The crystalline structure of the bioceramic powder and coating was investigated by X-ray diffraction (XRD). The powder was analyzed in symmetric geometry $(\theta-\theta)$ using a Bruker D8 Advance diffractometer with $\mathrm{CuK}_{\alpha}(\lambda=1.5418 \AA)$ radiation (Bruker, Karlsruhe, Germany), equipped with a high-efficiency LynxEye ${ }^{\mathrm{TM}} 1 \mathrm{D}$ linear detector, while the film was measured in grazing incidence (GIXRD) geometry, with a Rigaku SmartLab $3 \mathrm{~kW}$ equipment (Rigaku, Tokyo, Japan), using $\mathrm{CuK}_{\alpha}$ radiation $(\lambda=1.5418 \AA)$ and an incidence angle of $0.5^{\circ}$. The patterns were acquired in the $2 \theta$ range $9-60^{\circ}$, with a step size of $0.02^{\circ}$, and a dwell time of $5 \mathrm{~s}$ (for the powder) and $8.5 \mathrm{~s}$ (for the film).

(f) The chemical structure and the presence of functional groups were assessed in the case of both synthesized biocomposite powder and coating by Fourier transform infra-red (FTIR) spectroscopy in attenuated total reflectance (ATR) mode, using a Perkin Elmer Spectrum BX II spectrometer (Perkin Elmer, Waltham, MA, USA) equipped with a Pike-MIRacle ATR head with diamond-ZnSe crystal plate, having a diameter of $1.8 \mathrm{~mm}$ (Pike Technologies, Madison, WI, USA). The spectra were acquired in the $500-4000 \mathrm{~cm}^{-1}$ spectral range, at a resolution of $4 \mathrm{~cm}^{-1}$, and represented the average of 32 individual scans.

(g) The adhesion/cohesion strength of the 10MgHAp-Dex-thyme coating was tested by the pull-off method, complying with the ASTM D4541-17 "Standard test method for pull-off strength of coatings using portable adhesion testers" standard. A DFD ${ }^{\circledR}$ Instruments PAT MICRO AT101 dedicated machine (DFD ${ }^{\circledR}$ Instruments, Kristiansand, Norway) was employed. The testing procedure has been described in detail in [42]. The coating was cleanly detached from the surface. The adhesion strength was computed from the recorded failure value divided by the quantified detached surface area of the coatings. The average adherence value and SDs were calculated.

\subsection{In Vitro Antimicrobial activity}

The antimicrobial properties of $10 \mathrm{MgHAp}-$ Dex-thyme suspension and coating were tested against common Gram-positive (S. aureus, ATCC ${ }^{\circledR}$ 25923; E. faecalis, ATCC ${ }^{\circledR} 29212$ ) and Gram-negative (E. coli ATCC $^{\circledR}$ 25922, P. aeruginosa ATCC ${ }^{\circledR}$ 27853) bacterial, as well as fungal (C. albicans, ATCC ${ }^{\circledR}$ 90029), reference strains. The antimicrobial activity of the samples was assessed by performing quantitative antimicrobial assays by serial microdilution method ( 96 well plates) in a liquid medium. For this purpose, $10 \mu \mathrm{L}$ of microbial suspension of each microorganism, having a density of $10^{6} \mathrm{CFU} / \mathrm{mL}$ (CFU-colony forming units), was seeded in the wells. The cells were incubated at $37^{\circ} \mathrm{C}$ for 24,48 , and $72 \mathrm{~h}$ in the presence of $10 \mathrm{MgHAp}$-Dex-thyme suspension and coating. After each time interval, the plates were washed with phosphate-buffered saline solution and then treated with methanol to fix the adherent cells. The formed biofilm was evidenced using a purple crystal solution. The quantification of the antimicrobial activity of the 10MgHAp-Dex-thyme suspensions and layers against the microbial biofilm formation was performed by reading the absorbance of the microbial suspensions at $492 \mathrm{~nm}$. The experiments were done in triplicate, and the results were presented as means \pm SDs.

\section{Results and Discussion}

Information on the stability of the 10MgHAp-Dex-thyme suspension was obtained by both $\mathrm{ZP}$ and ultrasound measurements. ZP is a significant indicator of the stability of the suspensions. Figure 1 shows the $\mathrm{ZP}$ distribution obtained for the $10 \mathrm{MgHAp}$-Dex-thyme suspension. The value obtained for the $\mathrm{ZP}$ as a result of the measurements was $-37.2 \pm 2.3 \mathrm{mV}$, thus indicating good stability of the $10 \mathrm{MgHAp}$-Dex-thyme suspension. This result was in agreement with the previous studies conducted by Patel and Agrawal [43], which showed that for values $> \pm 30 \mathrm{mV}$, the suspensions had good stability. It has been reported that for $\mathrm{ZP}$ values of $\pm 0-10 \mathrm{mV}$ and $\pm 10-20 \mathrm{mV}$, the suspensions are extremely unstable 
and relatively stable, respectively, while for $\mathrm{ZP}$ values of $\pm 20-30 \mathrm{mV}$, one can speak of moderately stable dispersions [43]. Suspensions with good stability have a ZP with values $> \pm 30 \mathrm{mV}$ [43]. Furthermore, in our previous study [30], we confirmed by ultrasound measurements that a $\mathrm{ZP}$ value of $-17 \pm 3.4 \mathrm{mV}$ indicated that the suspension (10MgHAp nanoparticles in water) was unstable. Unfortunately, in reality, the problem is far more complex. Although ZP provides indications for suspension stability, it does not reflect the whole image as ZP determinations are not possible on concentrated suspensions. Thus, for a more accurate evaluation of the stability of the 10MgHAp-Dex-thyme suspension, ultrasonic measurements were performed. The ultrasound measurements were carried out on the concentrated suspensions obtained following the synthesis process.

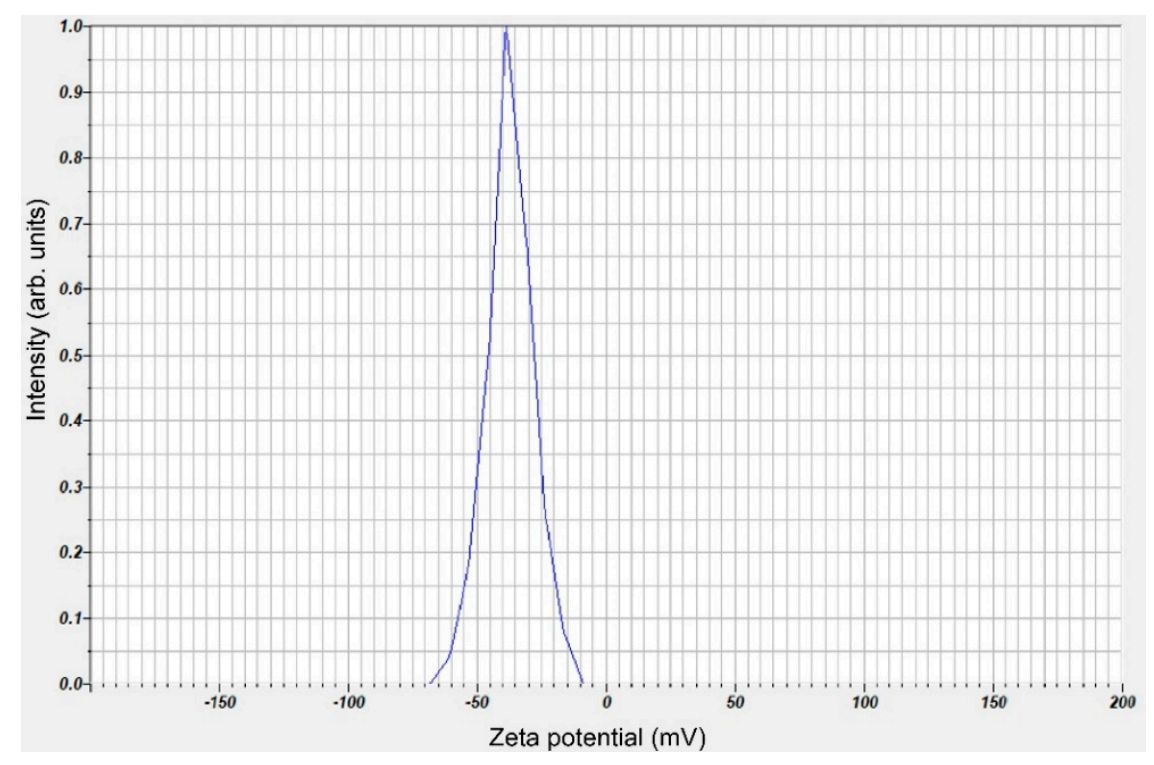

Figure 1. Zeta-potential of dextran-thyme magnesium-doped hydroxyapatite (10MgHAp-Dex-thyme) nanoparticles in suspension.

Ultrasound pulses were sent through the 10MgHAp-Dex-thyme concentrated suspension immediately after shaking stopped. The evolution of the signals over time provided information on the temporal stability of the suspension and the attenuation. The study was performed according to the first three recorded echoes. The first one had the shortest distance of $30 \mathrm{~mm}$, traveled through the suspension, and was less influenced by the scattering of the acoustic field and by the internal damping of the transducers.

An accurate determination of the speed of the ultrasound in the sample was made according to the time delays between the first three recorded echoes by the 10MgHAp-Dex-thyme suspension and those of the reference fluid (i.e., water). Thus, the speed in 10MgHAp-Dex-thyme concentrated suspension was $\mathrm{c}=1542.85 \pm 0.13 \mathrm{~m} / \mathrm{s}$, while in the reference fluid, it had a value of $\mathrm{c}_{0}=1498.84 \mathrm{~m} / \mathrm{s}$. Due to the fact that the difference between the speed of the analyzed suspension and that of the reference fluid is very small, a rigorous characterization of the evolution over time could not be achieved according to the speed of the sample ultrasound. A more significant variation was determined for the maximum transmitted signal amplitudes vs. recording moments (Figure 2). There was a slow and continuous variation of the amplitudes, which would be used for further processing. During the $4100 \mathrm{~s}$ recording time, the suspension did not precipitate. After $2500 \mathrm{~s}$, a slight increase of amplitudes occurred, but the tendency was not towards higher amplitudes as in the case of precipitation, but rather indicated particle flocculation. The commonly encountered passage in front of the transducers from the separation surface has not appeared in this case.

The long-time-interval of $2500 \mathrm{~s}$ was relevant for the stability of this particular suspension. During this period, the amplitude value of the first echo had a slow increase. It should be noted that the 
amplitude of the first echo was measured with the highest accuracy. The slope of the amplitude of the first echo vs. time was related to the stability parameter. In this case, the slope of this amplitude vs. time was $s=\frac{1}{A_{m}}\left|\frac{d A}{d t}\right|=1.35 \times 10^{-5}(1 / \mathrm{s})$, where $A_{m}$ represents the averaged amplitude of the signals. A small value of the slope of this amplitude vs. time showed excellent stability. It is reminded here that for pure water, $s=0$. The suspension had a typical signature in the frequency spectrum of the first transmitted echo (Figure 3).

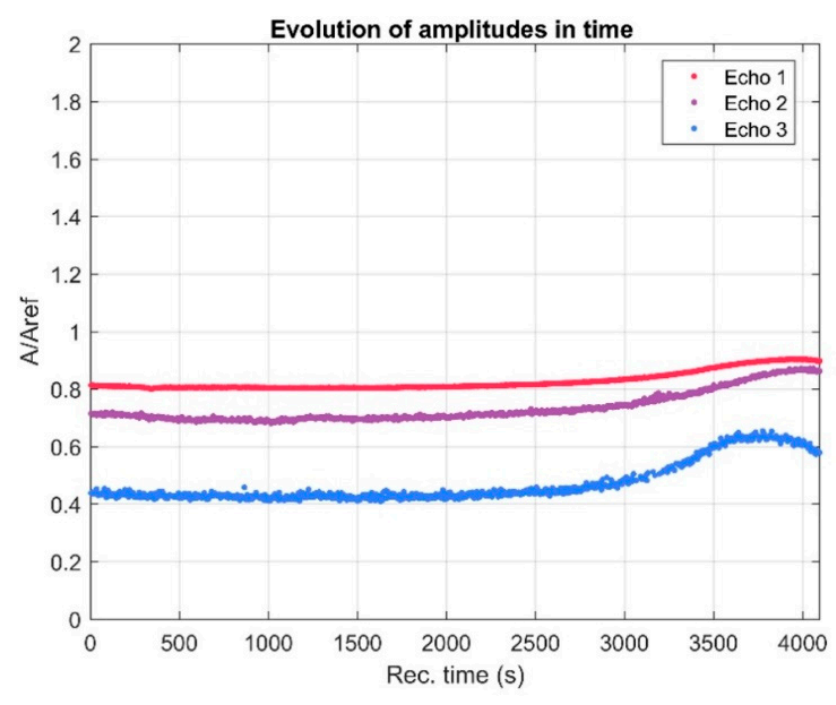

Figure 2. Relative amplitudes evolution vs. recording moments.

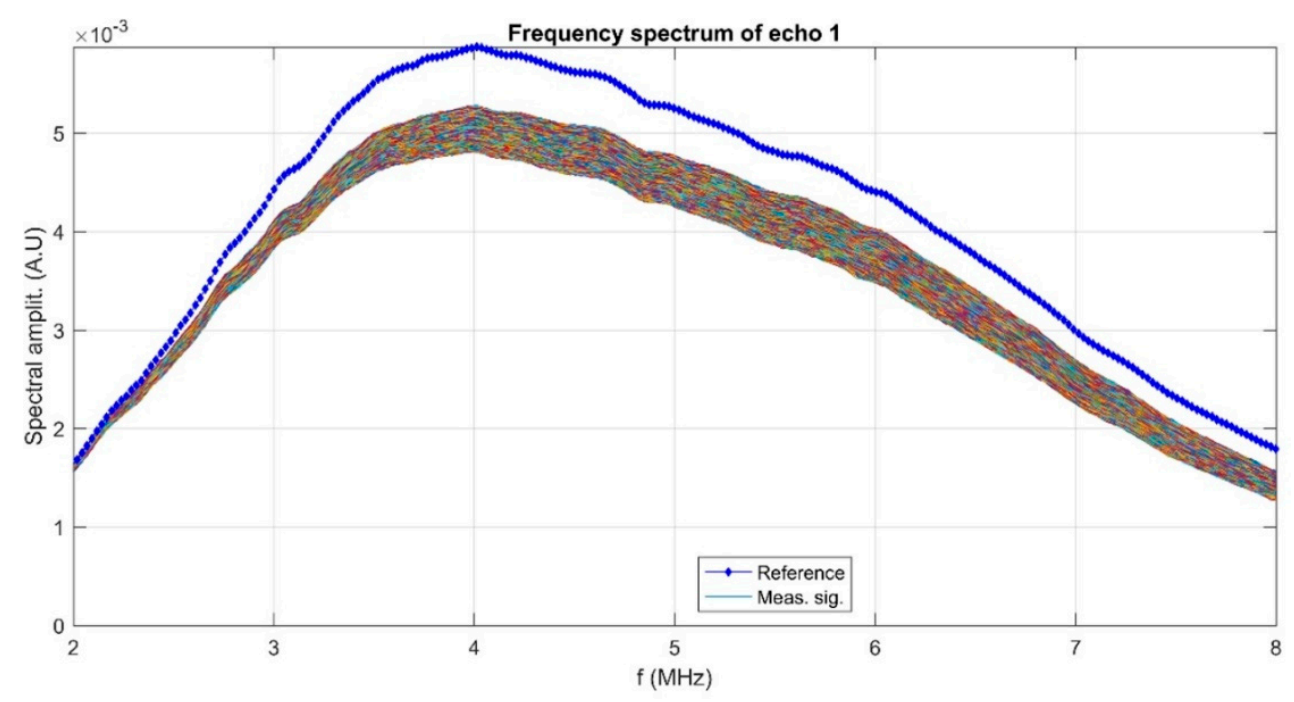

Figure 3. The frequency spectrum of the first transmitted echo. Reference fluid ( $\downarrow)$ and all recorded echoes superposed (many colors).

As can be seen in Figure 3, the upper curves corresponded to the asymptotic sedimentation of the 10MgHAp-Dex-thyme suspension, while the lowest curves corresponded to the first period of sedimentation. The maximum at $4 \mathrm{~K}$ was a feature of the transducers. The spectrum for the reference fluid was indicated by blue markers. The larger differences between the sample and the reference indicated a higher attenuation at the respective frequency. A more detailed analysis at several frequencies was done in the following analysis with respect to the variation of the spectral amplitude during the experiment duration. The recorded first echo was separated into harmonic components using Fourier series of frequencies between 2 and $8 \mathrm{MHz}$ (Figure 4). It could be seen that the component 
at $2 \mathrm{MHz}$ tended to a relative amplitude of 1 , meaning that the suspension became transparent to signals at this frequency, after $1 \mathrm{~h}$. All higher frequencies exhibited a continuous increasing path for their relative amplitudes from a minimum of 0.72 towards 0.93 during the long recording interval. The higher frequencies tended towards maxima after $3900 \mathrm{~s}$, which constituted a specific behavior of this suspension.

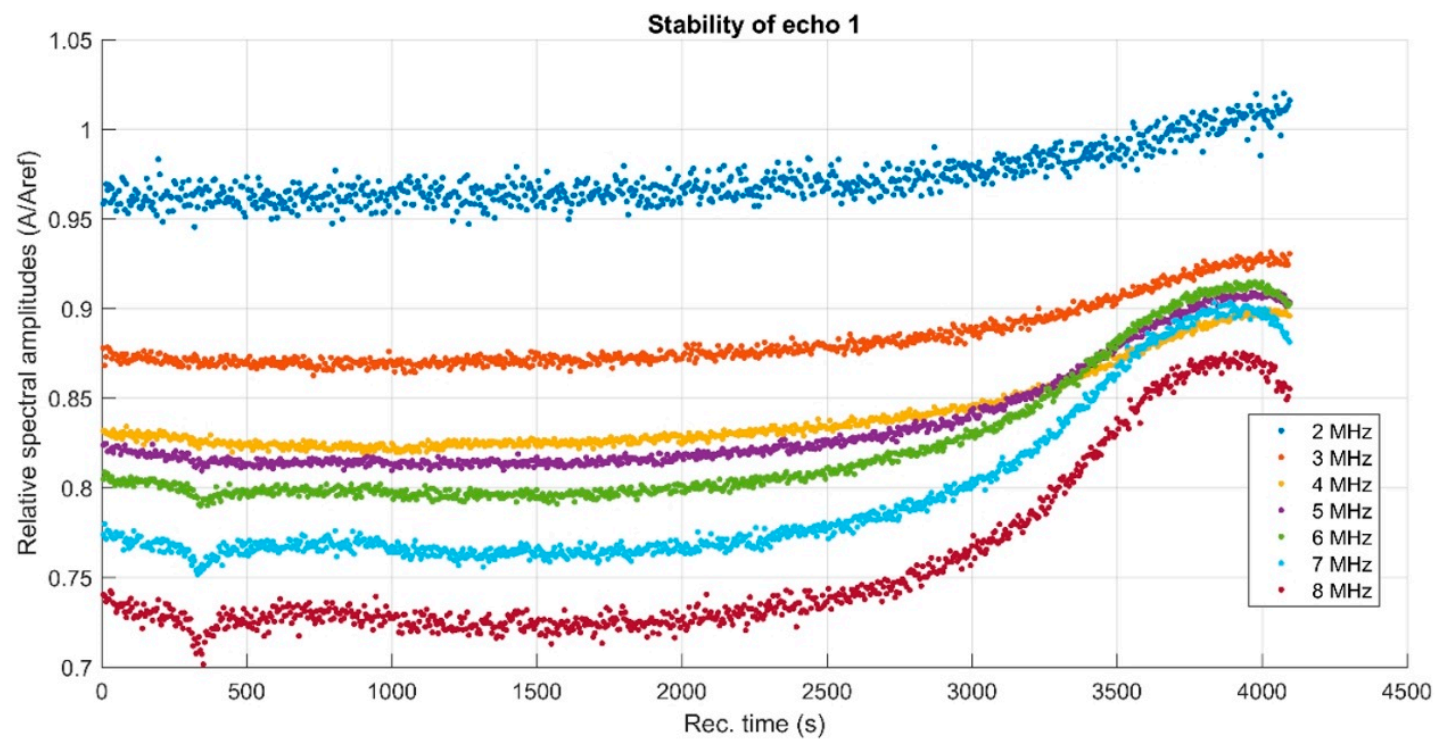

Figure 4. Spectral amplitudes relative variation vs. time, for the first echo.

More explicit information regarding the stability of the studied suspension was given by the frequency attenuation dependence for the first transmitted echo. Figure 5 shows the attenuation vs. frequency for the first transmitted echo by $10 \mathrm{MgHAp}$-Dex-thyme suspension compared to the same dependency on frequency for the reference fluid. The attenuation was considerably higher (1-10.7 nepper/m) for the 10MgHAp-Dex-thyme suspension with respect to the water used as a reference fluid $(0.3-1.3$ nepper $/ \mathrm{m})$.

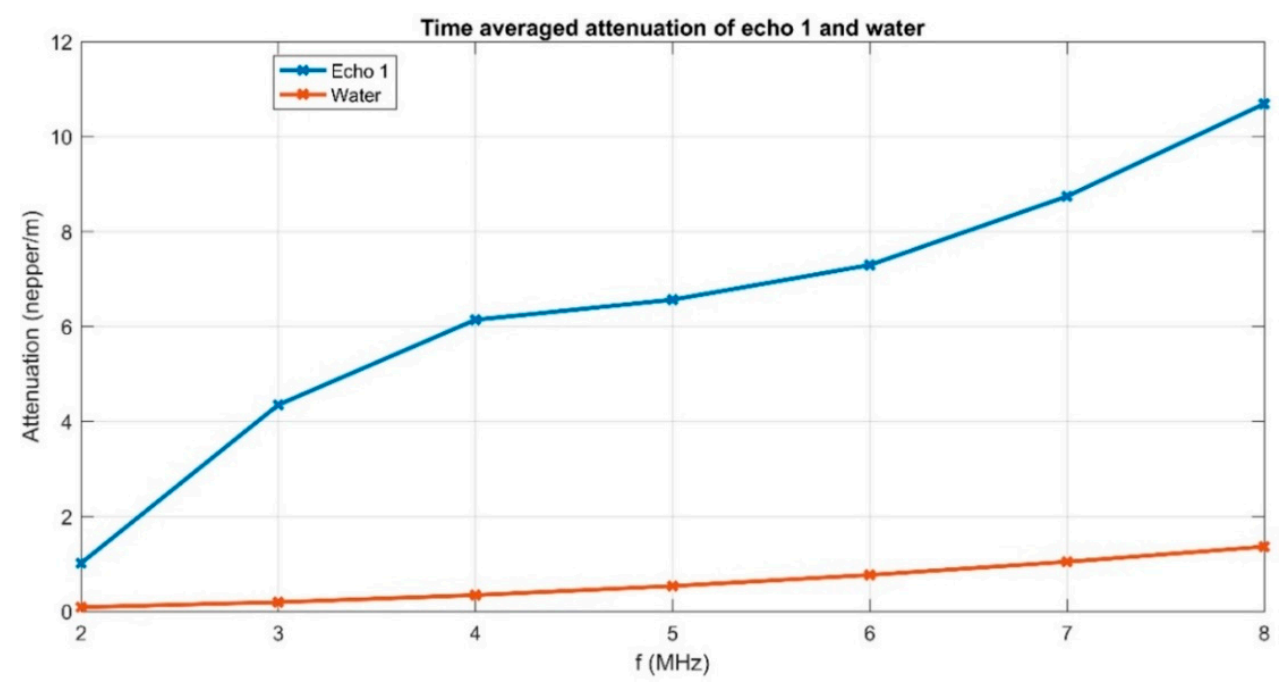

Figure 5. Attenuation vs. frequency for the first transmitted echo.

The attenuation determined for each spectral component depended on the echo-reading moment during the experiment, as shown in Figure 6. After about $5 \mathrm{~min}$, the highest frequencies in the spectrum indicated a small peak, which could be attributed to flocculation. 
Overall, the attenuation was slowly decreasing for all frequencies-a normal fact in the sedimentation process. A specific phenomenon for the 10MgHAp-Dex-thyme suspension was the temporary minimization of the attenuation, after about $1 \mathrm{~h}$ of acoustic monitoring, visible mostly for the high-frequency spectral components. The attenuation at the frequency of $8 \mathrm{MHz}$ was about 12 nepper/m for a long period, which was a large value, and it was owned to the small size of the nanoparticles.

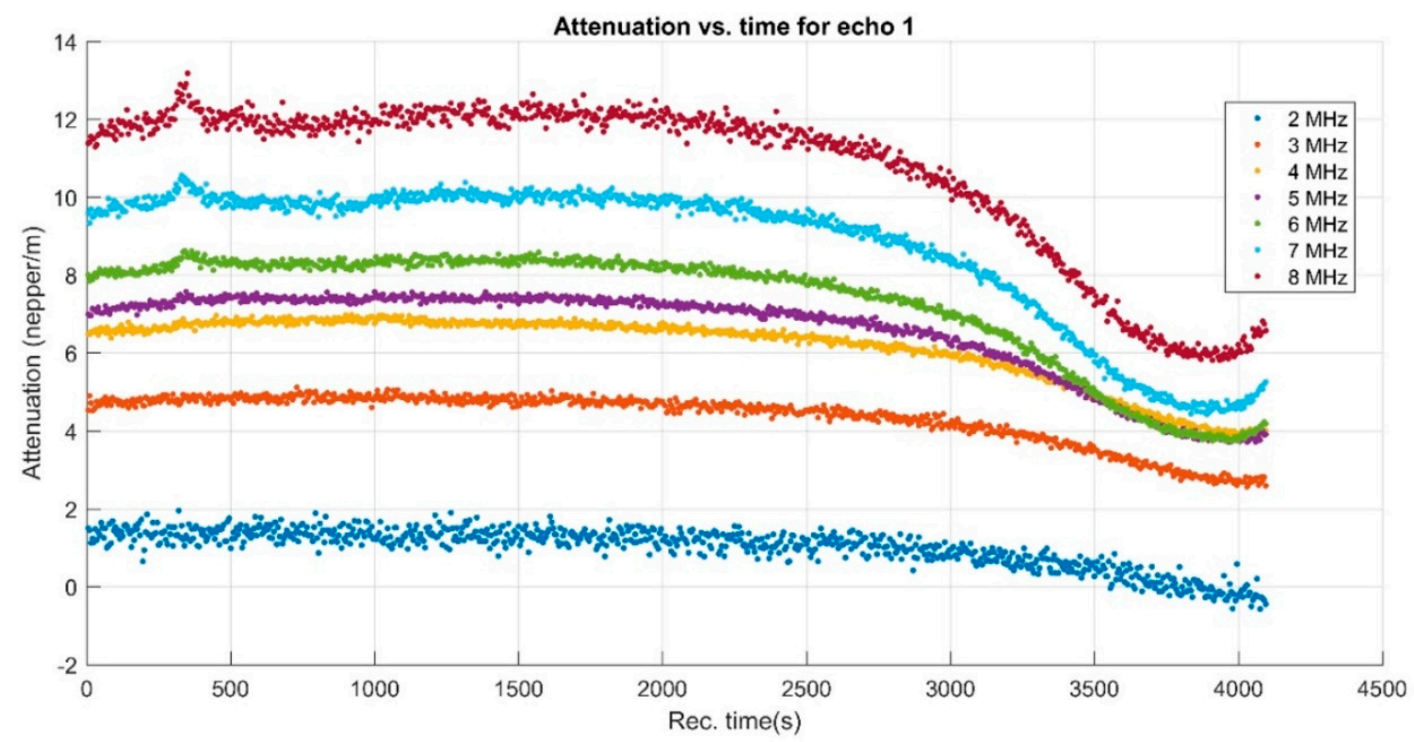

Figure 6. Attenuation vs. time for the spectral components of echo 1.

The morphology and size of the nanoparticles (of suspension) and grains (forming the coating) were examined by SEM analysis (Figure 7). A drop of the 10MgHAp-Dex-thyme suspension was deposited on a carbon band and analyzed after being dried under vacuum at RT. Upon drying, the 10MgHAp-Dex-thyme suspension agglomerated into large grains (Figure 7a), consisting of small particles with a spheroid-like shape and nanometric size (Figure $7 \mathrm{~b}$ ).

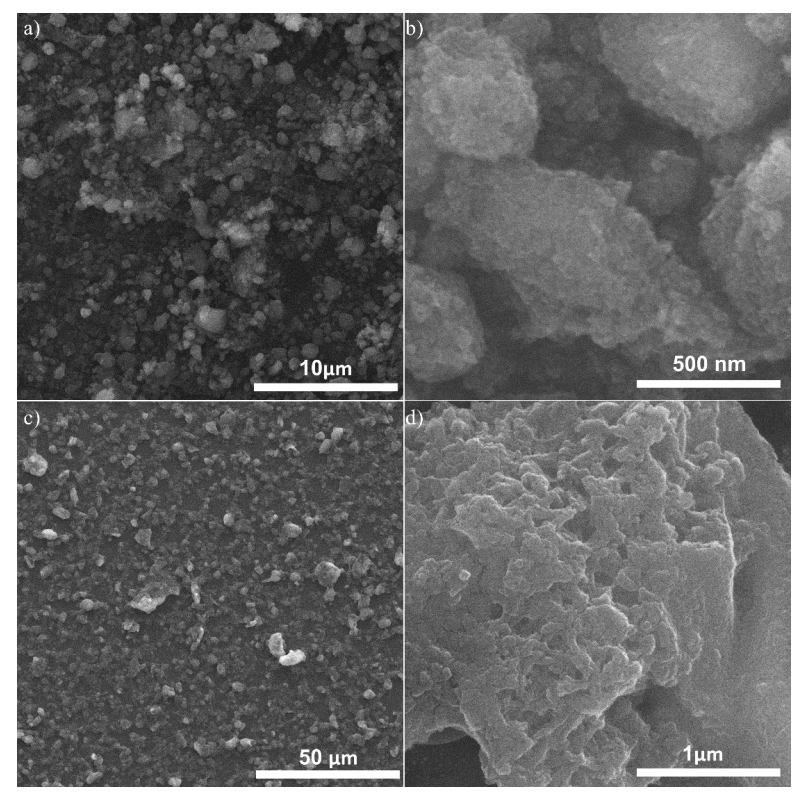

Figure 7. SEM $(\mathbf{a}, \mathbf{c})$ low and $(\mathbf{b}, \mathbf{d})$ high magnification micrographs of: $(\mathbf{a}, \mathbf{b})$ 10MgHAp-Dex-thyme nanoparticles and (c,d) surface of the 10MgHAp-Dex-thyme coating. 
The surface of the 10MgHAp-Dex-thyme coating, produced by dip-coating procedure, was homogeneous, devoid of variations, being covered evenly with uniform cobblestone-like grains, as could be seen in the general-view image presented in Figure 7c. The cobblestone-like grains that cover the surface were arranged regularly without voids, forming a compact film. At higher magnification (Figure 7d), it could be clearly seen that these coating grains were formed of particles with nanometric dimensions.

The EDS mapping analysis revealed a uniform distribution of the component chemical elements (i.e., $\mathrm{Ca}, \mathrm{P}, \mathrm{Mg}$, $\mathrm{O}$, and $\mathrm{C}$ ) (Figure $8 \mathrm{a}-\mathrm{f}$ ) into the $10 \mathrm{MgHAp}$-Dex-thyme coating. $\mathrm{A} \mathrm{Mg} /(\mathrm{Mg}+\mathrm{Ca}$ ) content of $\sim 8.8 \pm 0.4$ at. $\%$ and a $\mathrm{Ca} / \mathrm{P}$ molar ratio of $1.43 \pm 0.03$ were estimated by the EDS quantitative analyses. Thereby, the $\mathrm{Mg} /(\mathrm{Mg}+\mathrm{Ca})$ concentration was situated rather close to the intended compositional value (i.e., 10 at.\%), while the lesser $\mathrm{Ca} / \mathrm{P}$ molar ratio with respect to the stoichiometric value of pure HAp (i.e., $\approx 1.67$ ) suggested the successful incorporation of $\mathrm{Mg}$ cations into the HAp lattice.
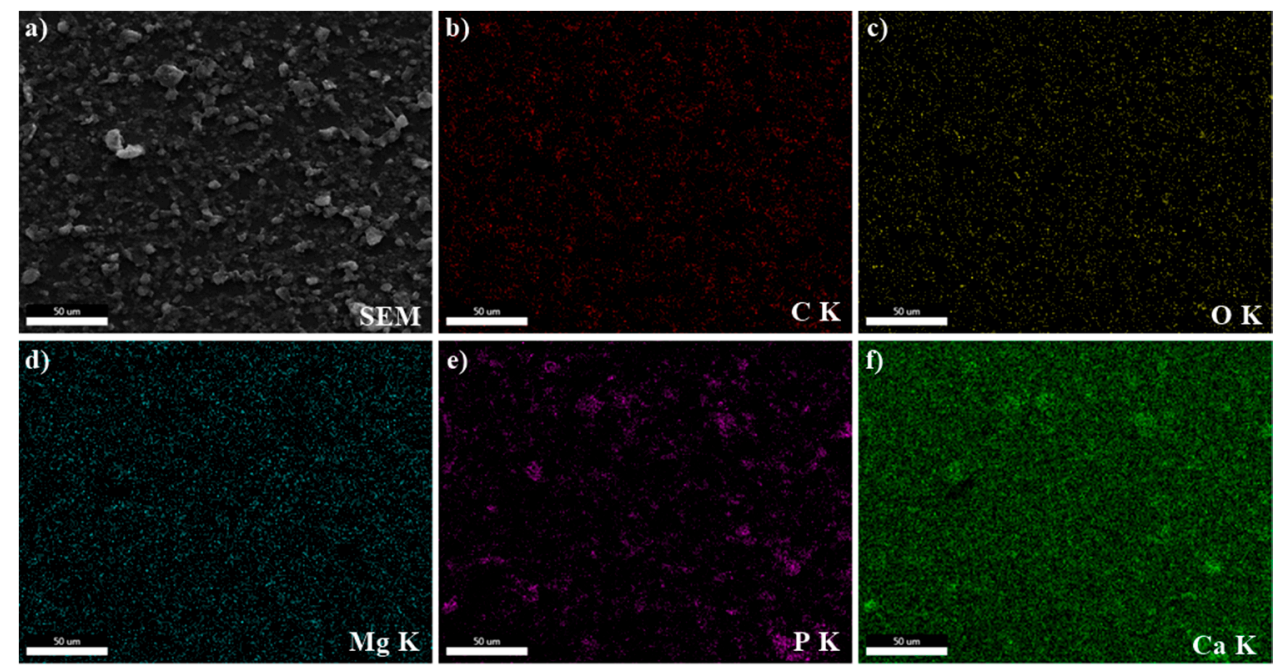

Figure 8. Elemental EDS mapping analysis of the 10MgHAp-Dex-thyme coating: (a) selected microscopic SEM field; (b) C K; (c) O K; (d) Mg K; (e) P K, and (f) Ca K. Scale bar: $50 \mu \mathrm{m}$.

The XRD patterns of the simple and dextran/thyme oil blended 10MgHAp powders (recorded in symmetric geometry) and of the 10MgHAp-Dex-thyme coating (collected in grazing incidence mode) are presented comparatively in Figure 9. All samples, irrespective of the form (i.e., powder or coating), elicited broad diffraction maxima indicative of their nano-scale character. Although overlaid, the diffraction peaks endorsed that both powders and coating consist of a hydroxyapatite-like compound (ICDD-PDF4: 00-009-0432). The Rietveld whole pattern fitting [44] allowed to estimate the lattice parameters and the average crystallite size of the powders (Table 1). Please note that the quantitative Rietveld evaluations should be considered only as estimations, as the fitting results were not completely satisfactory, irrespective of the efforts dedicated to this specific task. The quantitative assessments suggested that the $a$-lattice parameter $(a=9.549-9.551 \AA)$ and the average crystallite size remained virtually constant $(\sim 3.2-3.6 \mathrm{~nm})$, while the $c$-lattice parameter was only slightly increased in the case of the 10MgHAp-Dex-thyme blended material with respect to the simple 10MgHAp compound. The noisier nature of the GIXRD pattern of the coating did not permit us to perform a Rietveld fitting. However, the even broader allure of the diffraction peaks of the 10MgHAp-Dex-thyme coating advocated for a decrease of the average crystallite size with respect to the source material. 
Table 1. Lattice parameters and average crystallite size for the magnesium-doped hydroxyapatite (10MgHAp) and dextran-thyme magnesium-doped hydroxyapatite (10MgHAp-Dex-thyme) powders (as extracted by Rietveld whole pattern fitting).

\begin{tabular}{|c|c|c|c|}
\hline SAMPLE TYPE & $a$-lattice Constant ( $\mathrm{A})$ & $c$-lattice Constant $(\AA)$ & Average Crystallite Size (Å) \\
\hline 10MgHAp powder & $9.549 \pm 0.06$ & $6.796 \pm 0.03$ & $\sim 36$ \\
\hline 10MgHAp-Dex-thyme powder & $9.551 \pm 0.05$ & $6.848 \pm 0.03$ & $\sim 32$ \\
\hline 10MgHAp-Dex-thyme coating & $\mathrm{n} / \mathrm{a}$ & $\mathrm{n} / \mathrm{a}$ & $\mathrm{n} / \mathrm{a}$ \\
\hline
\end{tabular}

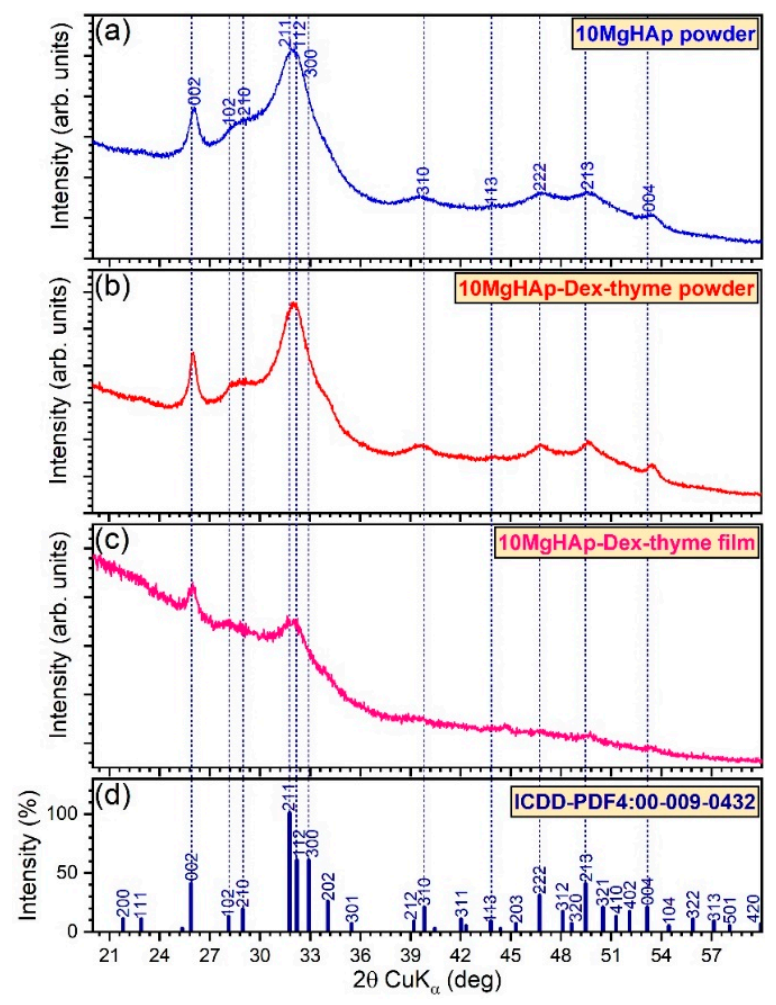

Figure 9. Comparative XRD patterns collected in the (a,b) Bragg-Brentano and (c) grazing incidence geometry for the (a) 10MgHAp powder, (b) 10MgHAp-Dex-thyme powder, and (c) 10MgHAp-Dex-thyme coating. (d) The lines of the ICDD-PDF4: 00-009-0432 reference file of hexagonal hydroxyapatite (HAp).

The FTIR-ATR spectra of simple 10MgHAp powders, 10MgHAp-Dex-thyme powder, and coating are presented comparatively in Figure 10, together with the reference spectra of raw dextran powder and thyme oil. The vibration bands distinctive to a B-type carbonated hydroxyapatite $[30,45-48]$ were evidenced for all studied bioceramic-based materials, i.e., $v_{4}$ bending $\left(\sim 558\right.$ and $\left.\sim 599-600 \mathrm{~cm}^{-1}\right), v_{1}$ symmetric stretching $\left(\sim 950-951 \mathrm{~cm}^{-1}\right)$, and $v_{3}$ asymmetric stretching $\left(\sim 1004-1013\right.$ and $\left.\sim 1097-1099 \mathrm{~cm}^{-1}\right)$ of $\left(\mathrm{PO}_{4}\right)^{3-}$ groups; libration of structural $(\mathrm{OH})^{-}$units $\left(\sim 630 \mathrm{~cm}^{-1}\right)$; and $v_{2}$ bending $\left(\sim 872-873 \mathrm{~cm}^{-1}\right)$ and $v_{3}$ asymmetric stretching $\left(\sim 1418-1424\right.$ and $\left.\sim 1456-1478 \mathrm{~cm}^{-1}\right)$ vibrations of $\left(\mathrm{CO}_{3}\right)^{2-}$ groups (Figure 10a,b,d,e,g,h). All materials were strongly hydrated, as evidenced by the intense wide bands appertaining to the bending $\left(\sim 1630-1640 \mathrm{~cm}^{-1}\right)$ and stretching $\left(\sim 2700-3700 \mathrm{~cm}^{-1}\right)$ vibrations of adsorbed water molecules (Figure 10c,f,i) [30,45-48]. The IR bands of HAp were broad, attesting a certain structural disorder prompted by the incorporation of large amounts of $\mathrm{Mg}$ (i.e., 10 at. \%) into the HAp lattice [30]. In the case of 10MgHAp-Dex-thyme powder and coating, supplemental IR maxima were evidenced in the spectral regions not superimposed by the more prominent HAp characteristic vibration modes, namely: vibrations of $\alpha-(1,3)$ linkages of glycoside units in dextran $\left(\sim 760-761 \mathrm{~cm}^{-1}\right)$ [49-53], out-of-plane wagging vibrations of $\mathrm{C}-\mathrm{H}$ in thymol units $\left(\sim 818 \mathrm{~cm}^{-1}\right.$, more evident in the case of the powder) [54-56], vibrations of $\alpha-(1,3)$ linkages of glycoside units in dextran $\left(\sim 918 \mathrm{~cm}^{-1}\right.$, more evident 
in the case of the coating) [49-52], stretching $(v)$ vibrations of $\mathrm{C}-\mathrm{O}-\mathrm{C}$ covalent bonds and glycosidic bridges in dextran $\left(\sim 1075,1150-1157\right.$ and $\left.1206-1209 \mathrm{~cm}^{-1}\right)$ [49-52], stretching $(v)$ vibrations of $C-\mathrm{O}$ in thyme $\left(\sim 1244 \mathrm{~cm}^{-1}\right)$ [54-56], bending $(\delta)$ vibrations of $\mathrm{C}-\mathrm{OH}$ in dextran $\left(\sim 1275-1280 \mathrm{~cm}^{-1}\right)$ [49-52], bending $(\delta)$ vibration of $\mathrm{C}-\mathrm{H}$ in dextran $\left(\sim 1348-1350 \mathrm{~cm}^{-1}\right)$ [52], and stretching $(v)$ vibrations of $\mathrm{C}-\mathrm{H}$ bonds in dextran and thyme $\left(\sim 2889,2920-2934,2973-2979 \mathrm{~cm}^{-1}\right)[50,52,54-57]$. Only slight peak shifts (of HAp, Dex, and thyme specific IR absorption bands) were noticed in the case of the coating with respect to the blended source powder or raw components. A complete assignment of the IR bands elicited by both the blended and raw materials is given in Table 2. As a general observation, all the components of the source blended powder were well-replicated into the structure of the coating. However, the coating IR absorption spectrum appeared to be convoluted with respect to the source blended powder, with a more conspicuous contribution of the Dex (majorly) for the former. A possible explanation resides in the partial loss by the dissolution of the nano-sized HAp component in the aqueous medium used for the coating synthesis.

The 10MgHAp-Dex-thyme layer deposited by dip-coating technique onto glass slides had a pull-off adhesion strength value of $36.3 \pm 2.4 \mathrm{MPa}$. The recorded adherence value was rather promising, being higher than the $15 \mathrm{MPa}$ limit imposed by the current international standard, which specifies the requirements of ceramic hydroxyapatite coatings to be applied to metallic or non-metallic load-bearing surgical implants (ISO 13779-2:2008 "Implants for surgery-Hydroxyapatite-Part 2: Coatings of hydroxyapatite").
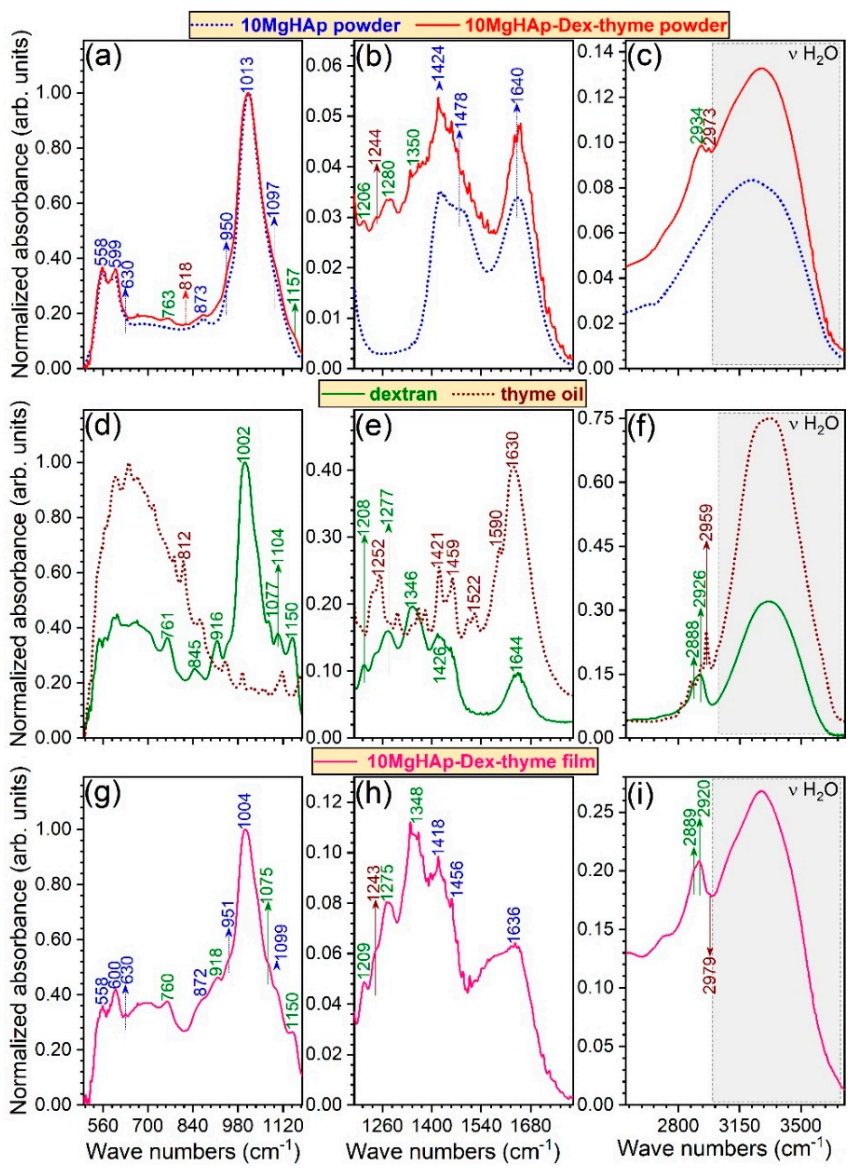

Figure 10. Comparative FTIR-ATR spectra of the (a-c) 10MgHAp (dotted line) and 10MgHAp-Dex-thyme powders (solid line); (d-f) dextran and thyme essential oil raw materials; and (g-i) 10MgHAp-Dex-thyme coating, zoomed over three relevant $(\mathbf{a}, \mathbf{d}, \mathbf{g})$ fingerprint and $(\mathbf{b}, \mathbf{c}, \mathbf{e}, \mathbf{f}, \mathbf{h}, \mathbf{i})$ functional groups regions: (a,d,g) 500-1180 cm-1 ; (b,e,h) $1180-1800 \mathrm{~cm}^{-1}$; and (c,f,i) $2500-3750 \mathrm{~cm}^{-1}$. 
Table 2. Assignment of the FTIR-ATR spectroscopy vibration bands.

\begin{tabular}{|c|c|c|c|c|c|}
\hline \multicolumn{5}{|c|}{ SAMPLE TYPE } & \multirow[b]{2}{*}{ IR BAND ASSIGNMENT } \\
\hline $\begin{array}{l}\text { 10MgHAp } \\
\text { Powder }\end{array}$ & $\begin{array}{l}\text { Dextran } \\
\text { Powder }\end{array}$ & Thyme Oil & $\begin{array}{l}\text { 10MgHAp-Dex-thyme } \\
\text { Powder }\end{array}$ & $\begin{array}{l}\text { 10MgHAp-Dex-thyme } \\
\text { Coating }\end{array}$ & \\
\hline 558 & - & - & 558 & 558 & asymmetric bending $\left(v_{4}\right)$ vibrations of $\left(\mathrm{PO}_{4}\right)^{3-}$ groups in HA [30,45-48] \\
\hline 559 & - & - & 599 & 600 & asymmetric bending $\left(v_{4}\right)$ vibrations of $\left(\mathrm{PO}_{4}\right)^{3-}$ groups in $\mathrm{HA}[30,45-48]$ \\
\hline 630 & _- & _- & 630 & 630 & libration vibrations of $(\mathbf{O H})^{-}$structural groups in HA [30,45-48] \\
\hline - & 761 & - & 763 & 760 & vibrations of $\alpha-(1,3)$ linkages of glycoside units [49-53] \\
\hline - & - & 812 & 818 & - & out-of-plane wagging vibrations of $\mathbf{C}-\mathbf{H}$ in thymol units [54-56] \\
\hline- & 845 & - & - & - & vibrations of $\alpha-(1,3)$ linkages of glycoside units [49-52] \\
\hline 873 & - & - & 873 & 872 & symmetric stretching $\left(v_{2}\right)$ vibrations of $\left(\mathrm{CO}_{3}\right)^{2-}$ groups $[45,46]$ \\
\hline- & 916 & - & - & 918 & vibrations of $\alpha-(1,3)$ linkages of glycoside units [49-52] \\
\hline 950 & - & - & 950 & 951 & symmetric stretching $\left(v_{1}\right)$ vibrations of $\left(\mathbf{P O}_{4}\right)^{3-}$ groups in HA $[30,45,46]$ \\
\hline- & 1002 & - & - & - & vibrations of $\alpha-(1,6)$ linkages of glycoside units [49-52] \\
\hline 1013 & - & - & 1013 & 1004 & asymmetric stretching $\left(v_{3}\right)$ vibrations of $\left(\mathbf{P O}_{4}\right)^{3-}$ groups in HA $[30,45-48]$ \\
\hline- & 1077 & - & - & 1075 & stretching $(v)$ vibrations of $\mathbf{C}-\mathbf{O}-\mathbf{C}$ covalent bonds and glycosidic bridges [49-52] \\
\hline 1097 & - & - & 1097 & 1099 & asymmetric stretching $\left(v_{3}\right)$ of $\left(\mathbf{P O}_{4}\right)^{3-}$ groups in $\mathrm{HA}[30,45-48]$ \\
\hline- & 1104 & - & - & - & stretching $(v)$ vibrations of $\mathbf{C}-\mathbf{O}-\mathbf{C}$ covalent bonds and glycosidic bridges [49-52] \\
\hline - & 1150 & - & 1167 & 1150 & stretching $(v)$ vibrations of $\mathbf{C}-\mathbf{O}-\mathbf{C}$ covalent bonds and glycosidic bridges [49-52] \\
\hline - & 1208 & - & 1206 & 1209 & stretching $(v)$ vibrations of $\mathbf{C}-\mathbf{O}-\mathbf{C}$ covalent bonds and glycosidic bridges [49-52] \\
\hline - & - & 1252 & 1244 & 1243 & stretching $(v)$ vibrations of $\mathbf{C}-\mathbf{O}[54-56]$ \\
\hline - & 1277 & - & 1280 & 1275 & bending $(\delta)$ vibrations of $\mathrm{C}-\mathrm{OH}[53]$ \\
\hline - & 1346 & - & 1350 & 1348 & bending $(\delta)$ vibration of $\mathbf{C}-\mathbf{H}[52]$ \\
\hline - & - & 1421 & - & - & stretching $(v)$ vibrations of $\mathbf{C}-\mathbf{C}[54-56]$ \\
\hline 1424 & - & - & - & 1418 & asymmetric stretching $\left(v_{3}\right)$ vibrations of $\left(\mathrm{CO}_{3}\right)^{2-}$ groups $[30,45,46]$ \\
\hline - & 1426 & - & 1424 & - & bending $(\delta)$ vibrations of $\mathbf{O}-\mathbf{H}[52]$ \\
\hline - & - & 1459 & - & - & bending $(\delta)$ vibrations of $\mathbf{C}-\mathbf{H}[52]$ \\
\hline 1478 & - & - & 1478 & 1456 & asymmetric stretching $\left(v_{3}\right)$ of $\left(\mathrm{CO}_{3}\right)^{2-}$ groups $[30,45,46]$ \\
\hline- & - & 1522 & - & - & wagging vibrations of $\mathrm{C}-\mathrm{H}$ in $\mathrm{CH}_{3}$ units [53-56] \\
\hline - & - & 1590 & - & - & aromatic vibration domain and bending vibrations of $\mathbf{C}-\mathbf{H}$ [53-56] \\
\hline- & - & 1630 & - & - & $\begin{array}{l}\text { stretching }(v) \text { vibrations of } \mathbf{C}-\mathbf{H} \text { and bending }(\delta) \text { vibrations of adsorbed } \mathbf{H}_{2} \mathbf{O} \\
\text { molecules [53-56] }\end{array}$ \\
\hline 1640 & - & - & 1640 & 1636 & bending ( $\delta$ ) vibrations of adsorbed $\mathbf{H}_{\mathbf{2}} \mathbf{O}$ molecules $[30,45,48]$ \\
\hline- & 1644 & - & - & - & bending $(\delta)$ vibrations of bound water molecules [50] \\
\hline - & 2888 & - & - & 2889 & symmetric stretching $(v)$ vibrations of $\mathbf{C}-\mathbf{H}$ bonds $[50,52,57]$ \\
\hline - & 2926 & - & 2934 & 2920 & asymmetric stretching $(v)$ vibrations of $\mathbf{C}-\mathbf{H}$ bonds $[50,52,57]$ \\
\hline - & - & 2959 & 2973 & 2979 & asymmetric stretching $(v)$ vibrations of $\mathbf{C}-\mathbf{H}$ bonds $[50,52,54-57]$ \\
\hline $2700-3700$ & $2700-3700$ & $2700-3700$ & $2700-3700$ & $2700-3700$ & $\begin{array}{l}\text { stretching }(v) \text { vibrations of adsorbed } \mathrm{H}_{2} \mathrm{O} \text { molecules on the surface of } \mathrm{HAp},(\mathrm{OH})^{-} \\
\text {of polysaccharide }[30,45-48]\end{array}$ \\
\hline
\end{tabular}


Nowadays, due to the appearance of microorganisms resilient to conventional therapies, studies regarding the antimicrobial effects of various types of possible antimicrobial agents, such as metallic ions (copper, iron, silver, magnesium, zinc), inorganic nanoparticles, or essential oils, are performed in the search for efficient solutions with a wider action range against pathogens $[1,2,18,20,22,38,58]$. In this paper, we investigated for the first time, the influence of Mg-doped HAp enhanced with thyme essential oil in a dextran matrix, in both solution and coating form, on the development of microbial biofilms of some of the most prevalent fungal and Gram-positive and Gram-negative bacterial strains. The influence of the 10MgHAp-Dex-thyme suspensions and coatings against the development of microbial biofilm formation was assessed at three different time intervals (i.e., 24, 48, and $72 \mathrm{~h}$ ). The results of the antimicrobial assays of 10MgHAp-Dex-thyme suspensions and layers against Gram-positive (S. aureus, ATCC ${ }^{\circledR}$ 25923; E. faecalis, ATCC ${ }^{\circledR}$ 29212) and Gram-negative (E. coli, ATCC $^{\circledR}$ 25922; P. aeruginosa ATCC ${ }^{\circledR}$ 27853) bacteria, as well as fungal (C. albicans, ATCC ${ }^{\circledR}$ 90029) reference strains, are presented in Figure 11. Generally, a stronger antimicrobial activity was also noticed in the case of 10MgHAp-Dex-thyme suspension with respect to the 10MgHAp-Dex-thyme coating, for all testing time intervals. This was to be expected since the dispersed nanoparticles of powder would have a higher active surface area with respect to the one of a fairly-compact film, even if nanostructured, and thereby, an improved ability to interact with the biological medium and release antimicrobial elements.

After $24 \mathrm{~h}$, the biological tests demonstrated that 10MgHAp-Dex-thyme suspensions had strong antimicrobial properties in the case of Gram-positive S. aureus and Gram-negative P. aeruginosa bacterial strains (Figure 11), with respect to the control. Moreover, the results indicated that 10MgHAp-Dex-thyme coating exhibited also a good antimicrobial effect against the formation of the microbial biofilm after $24 \mathrm{~h}$ of incubation against Gram-positive S. aureus and Gram-negative P. aeruginosa. In a previous $10 \mathrm{MgHAp}$ study, it was shown that the pure HAp suspensions promoted the biofilm formation for all tested microbial strains at all the time intervals, and thereby, pinpointed the recorded antimicrobial properties to the presence of $\mathrm{Mg}$ ions incorporated into the HAp lattice [30]. On the other hand, the antimicrobial efficacy tests performed within this study demonstrated that both 10MgHAp-Dex-thyme suspension and coating inhibited the biofilm formation of P. aeruginosa for all tested concentrations ranging from 5 to $0.009 \mathrm{mg} / \mathrm{mL}$, while in the case of the $S$. aureus bacterial strain, the inhibition for 10MgHAp-Dex-thyme suspensions and layers was recorded in the $\sim 2.5-0.0039 \mathrm{mg} / \mathrm{mL}$ range. A small inhibition of the biofilm formation was obtained after $24 \mathrm{~h}$ in the case of the $C$. albicans fungal strain for concentrations ranging from 5 to $1.25 \mathrm{mg} / \mathrm{mL}$ of 10MgHAp-Dex-thyme (Figure 11).

Furthermore, the tests highlighted that the inhibitory effect against the microbial formation was conserved (in the case of S. aureus) and strongly enhanced (in the case of P. aeruginosa) after $72 \mathrm{~h}$ of incubation for both 10MgHAp-Dex-thyme suspension and coatings relative to the control.

The tested samples also exhibited a good inhibitory effect against $E$. faecalis and E. coli biofilm development for all tested concentrations and at all tested time intervals (Figure 11).

The results obtained in the case of the 10MgHAp-Dex-thyme suspensions highlighted that the suspension exhibited better antimicrobial properties than the previous reported 10MgHAp solutions tested on the same microbial strains at the same time intervals [30]. These results were attributed to the presence of the thyme $\mathrm{EO}$ in the samples and the stability of the suspension. The increase of stability could influence the efficiency of these suspensions against different bacterial or fungal strains. By increasing the stability, the antimicrobial properties could intensify as a result of a better distribution of the nanoparticles in suspension. In the present study, according to the ultrasound measurement results, a slight change in suspension stability was observed after $3000 \mathrm{~s}$, while in a previous study of the 10MgHAp solution [30], a drastic change in suspension stability was observed after only $100 \mathrm{~s}$. Consequently, the inhibition of the biofilm development was also stronger in the case of the 10MgHAp-Dex-thyme layers with respect to the one reported in [30] for the 10MgHAp solutions. The results obtained in our study were in good agreement with the literature in what concerns the antimicrobial properties of Mg-based composites and EO compounds [22,28,29,59-63]. 
Boskovic et al. [63] studied the antimicrobial activity of thyme (Thymus vulgaris) and oregano (Origanum vulgare) EOs against some food-borne microorganisms and demonstrated that both types of tested EOs exhibited a good antibacterial activity against various microorganisms, such as Salmonella enteritidis, Salmonella typhimurium, S. aureus, methicillin-resistant S. aureus (MRSA), E. coli, and Bacillus cereus. The antimicrobial activity against pathogenic bacteria S. aureus and L. monocytogenes of thyme EOs have also been reported by Carvalho et al. [23] at different time intervals. Therefore, the stronger antimicrobial activity elicited by both $10 \mathrm{MgHAp}$-Dex-thyme suspension and coating with respect to the efficacy of $10 \mathrm{MgHAp}$ solutions [30] could be attributed also to the supplemental presence of thyme EO. Few possible mechanisms responsible for the antimicrobial activity of $\mathrm{Mg}$ ions have been reported by different researchers $[59,60]$. The most prevalent mechanism responsible for the antimicrobial activity of $\mathrm{Mg}$ ions is their ability to infiltrate inside the bacterial cells and lead to an alteration of the cell's membrane by creating disturbances of the membrane potential [60]. Another mechanism, hypothesized to be involved in the antimicrobial activity of the Mg-containing compounds, is connected to the presence of high concentrations of $\mathrm{OH}^{-}$on the surface of $\mathrm{MgO}$ particles, which consequents in an increase of the $\mathrm{O}^{2-}$ concentration, responsible for the destruction of the bacterial cell wall [60]. On the other hand, the antimicrobial activity of the EOs is attributed to their chemical constituents, which could differ function of the type of plant, origin, harvesting time, and the part of the plant used for the oil extraction [62].

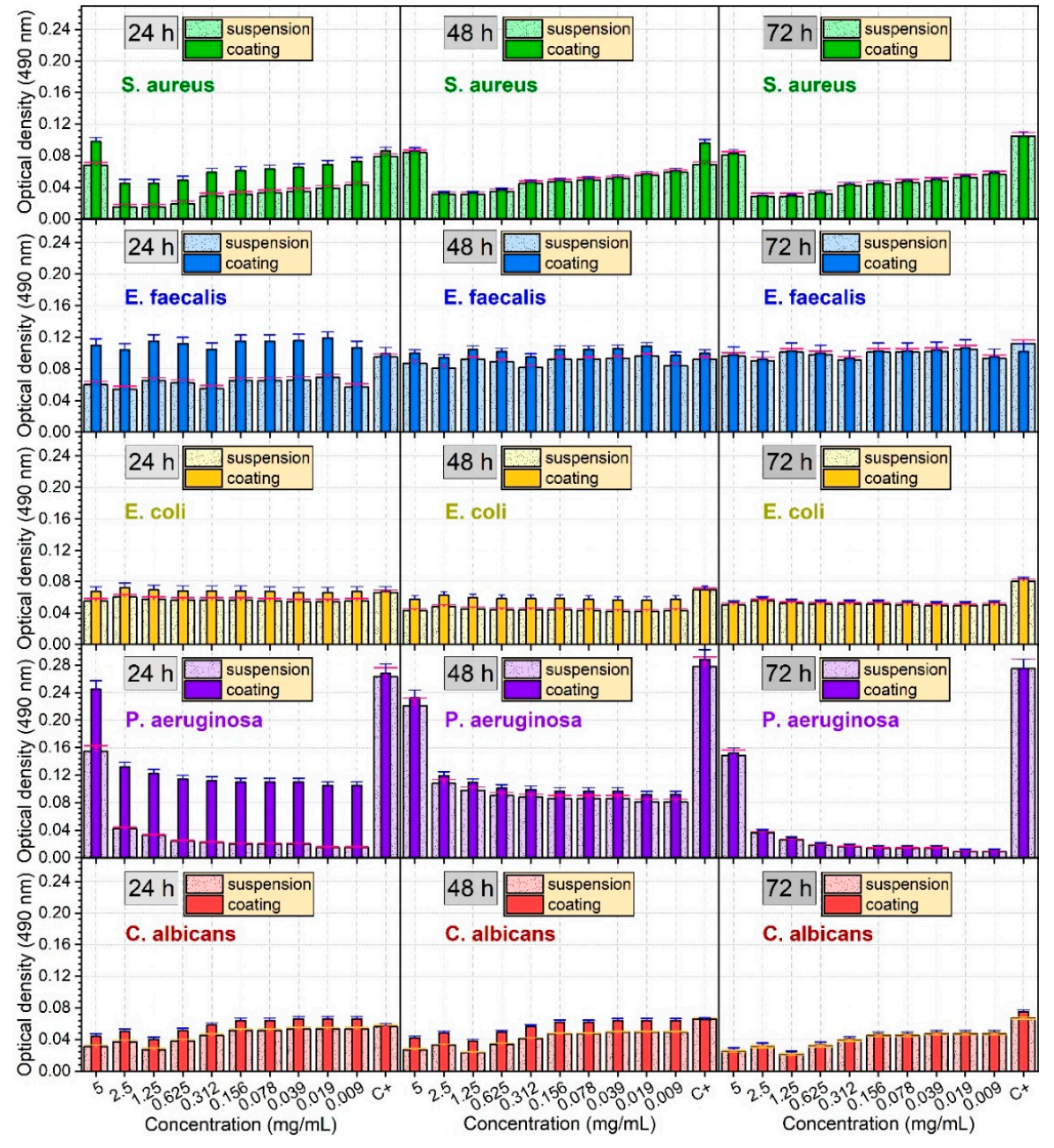

Figure 11. The dynamics of the antimicrobial activity of 10MgHAp-Dex-thyme suspension and coating against S. aureus (ATCC $\left.{ }^{\circledR} 25923\right)$, E. faecalis (ATCC $\left.{ }^{\circledR} 29212\right)$, E. coli (ATCC $\left.{ }^{\circledR} 25922\right)$, P. aeruginosa (ATCC ${ }^{\circledR}$ 27853), and C. albicans (ATCC ${ }^{\circledR}$ 90029) microbial cells after 24, 48, and $72 \mathrm{~h}$ of incubation. 
The safety and stability of the dextran-thyme coated magnesium-doped hydroxyapatite particle suspension make it a highly interesting nano-system for many biomedical applications.

Overall, the 10MgHAp-Dex-thyme suspensions and coatings exhibited strong (against S. aureus and P. aeruginosa strains) and moderate (against E. faecalis and E. coli strains) antibacterial properties over a period of $72 \mathrm{~h}$, relative to the control. Moreover, it was emphasized that the stability of the $10 \mathrm{MgHAp}$-Dex-thyme suspension allowed for the conservation of its physicochemical properties and the good replication of its antibacterial effect into the coatings. Due to their intended applicability (i.e., implant coatings), the long-term durability and intensity of the therapeutic effect imprinted by such type of layers would be of utmost biofunctional importance. The first post-surgical hours are considered to be critical for preventing implant infections as the microorganisms are not yet metabolically active [64]. An efficacious antimicrobial action could avert the bacterial multiplication of bacteria and the development of the biofilm. However, in the case of osteomyelitis (caused by bacterial infestation from contiguous contamination sources, e.g., during bone trauma or surgical interventions) or hematogenous osteomyelitis (caused by bacterial infestation from internal localized sources, e.g., a dental infection or entering through the bloodstream), delayed post-operative bone infections are known to occur [65]. For instance, in the case of prosthetic joint infections, early post-operative symptoms could arise within 1 month and are termed chronic when they are identified after more than 1 month since surgery [66]. Significantly delayed post-surgical infections ( 3 months-2 years after surgery) have also been reported $[65,67]$.

For such cases, a reliable implant coating should satisfy concomitantly three criteria: (i) stimulate a broad-spectrum antibacterial activity; (ii) elicit good stability and robustness over time; and (iii) possess a durable antimicrobial action, which can span for weeks or even months. In this context, several in vivo studies have already highlighted the merits of antibacterial HAp-based coatings and the persistence of their therapeutic effects in time [68-70]. Akiyama et al. [69] inspected in vivo the antibacterial activity of flame-sprayed silver-containing HAp (Ag-HAp) implant coatings in the medullary cavity of rat tibiae. The ability of Ag-HAp to prevent the development of acute and subacute infections after 4 weeks of implantation was demonstrated. Furthermore, Ueno et al. [70] tested in vivo (up to 7 days), by subcutaneous implantation on the back of rats, the antimicrobial effect of Ag-HAp flame-sprayed coatings against an MRSA strain. The Ag-HAp coatings significantly reduced the biofilm coverage rates of MRSA.

The prolongation of the antibacterial effect of HAp-based materials is presently under focus worldwide. For instance, Lian et al. [71] evaluated in vivo, using a rabbit model of chronic osteomyelitis, the antibacterial activity of vancomycin-loaded nanoHAp/collagen/calcium sulfate bone scaffold. The authors demonstrated that after 3 weeks, since the infection initiation and 12 weeks of treatment with vancomycin loaded nanoHAp/collagen/calcium sulfate composite, no evidence of infection was observed, while the formation of new trabecular bone was noticed at the implantation site. Furthermore, Townsend et al. [72] accomplished by a dual approach—covalently bonding of antimicrobial peptide (AMP) to HAp, followed by deposition of electrostatically bound AMPs-an effective coating design, which was proven to be stable for a period of over 12 months and had the potential to prevent implant colonization by both Gram-positive (S. aureus and Staphylococcus epidermidis) and Gram-negative (P. aeruginosa) bacteria.

However, even though more studies regarding the in vivo lastingness of coatings properties are currently emerging, there is still a lack of clinical evidence for further validation. Without a doubt, there is a persistent need to improve or delineate new implant coating designs, such as to achieve ideal releasing curves of the therapeutic agents over time. In this respect, our further studies will be dedicated to the assessment of the temporal stability of 10MgHAp-Dex-thyme type coatings (by monitoring the coating degradation and the active species temporal release curves) while searching for solutions to further improve their overall biological properties, aiming to extend their temporal antibacterial effectiveness. 


\section{Conclusions}

Stable suspensions of dextran-thyme coated magnesium-doped hydroxyapatite (10MgHAp-Dex-thyme) nanoparticles were obtained for the first time by an adapted chemical co-precipitation method. Further, based on this suspension, layers were successfully prepared by the dip-coating technique. The physicochemical properties and the antimicrobial efficiency (against a large array of pathogens) of the stable suspensions and coatings were evaluated. The XRD analysis confirmed that the doping (with $\mathrm{Mg}$ ) and blending (with dextran and thyme oil) did not induce the decomposition of the HAp phase, in the case of both 10MgHAp-Dex-thyme powder and coating. Further, the EDS mapping analysis indicated a uniform distribution of the constituting elements $(\mathrm{Ca}, \mathrm{P}$, $\mathrm{Mg}, \mathrm{O}$, and $\mathrm{C}$ ) in the coating and suggested the successful incorporation of Mg into the HAp lattice. A good bonding strength value of $\sim 36 \mathrm{MPa}$ was inferred for the 10MgHAp-Dex-thyme coating by the pull-off method. An increase in the antimicrobial activity of the 10Mg-HAp-Dex-thyme suspension by increasing the stability of the solution and the presence of thyme essential oil was highlighted. Moreover, the good antimicrobial efficacy, against fungal and Gram-positive and Gram-negative bacterial strains, of the 10Mg-HAp-Dex-thyme composite layers obtained from such solutions enriched with thyme EO could open paths toward the development of novel antimicrobial coatings for medical devices.

Even though Mg-based composites and EO compounds are reported to possess strong antibacterial activity, further researches are needed at a global level in order to gather all necessary evidence to elucidate the mechanisms involved in the antibacterial effects of coupled $\mathrm{Mg}$ ions and EOs on various threatening microorganisms. The duration of the antimicrobial effect needs to be thoroughly assessed, and solutions (if needed) to strengthen and/or prolong the antimicrobial effect of the composite implant coating would be surveyed in future studies. Furthermore, the biological and the mechanical performance of 10Mg-HAp-Dex-thyme coatings deposited onto titanium-based implant-type substrates will be explored by complex biocompatibility assays and nanoindentation, scratch and wear tests, respectively.

Author Contributions: Conceptualization, G.E.S., M.V.P., and D.P.; Methodology, G.E.S., M.V.P., and D.P.; Software, M.V.P.; Validation, G.E.S., D.P., M.M.-H., and M.V.P.; Formal Analysis, G.E.S., S.L.I., M.V.P., D.P., M.M.-H., C.M., and N.B.; Investigation, M.V.P., G.E.S., S.L.I., D.P., C.M., and N.B.; Resources, G.E.S., C.M., M.V.P., M.M.-H., and N.B.; Data Curation, D.P., S.L.I., and M.V.P.; Writing-Original Draft Preparation, D.P., G.E.S., S.L.I., M.V.P., M.M.-H., and N.B.; Writing-Review and Editing, D.P., S.L.I., and M.V.P.; Visualization, G.E.S., C.M., D.P., S.L.I., M.V.P., M.M.-H., and N.B.; Supervision, G.E.S., M.V.P., M.M.-H., and N.B.; Project Administration, M.V.P.; Funding Acquisition, G.E.S. All authors have read and agreed to the published version of the manuscript.

Funding: This research was partially funded by the Romanian Ministry of Research and Innovation, CCCDI-UEFISCDI, through the projects PN-III-P1-1.2-PCCDI-2017-0629/contract no. 43PCCDI/2018 and PN-III-P1-1.2-PCCDI-2017-0062/contract no. 58PCCDI/2018/component project no. 2.

Acknowledgments: This work was supported by the Romanian Ministry of Research and Innovation through the projects PN-III-P1-1.2-PCCDI-2017-0629/contract no. 43PCCDI/2018 and PN-III-P1-1.2-PCCDI-2017-0062/contract no. 58PCCDI/2018/component project no. 2. We thank A. Richard and A. Sauldubois from the "Centre de Microscopie Electronique" of the University of Orléans for assistance with SEM data acquisition.

Conflicts of Interest: The authors declare no conflict of interest.

\section{References}

1. Tite, T.; Popa, A.-C.; Balescu, L.M.; Bogdan, I.M.; Pasuk, I.; Ferreira, J.M.F.; Stan, G.E. Cationic substitutions in hydroxyapatite: Current status of the derived biofunctional effects and their in vitro interrogation methods. Materials 2018, 11, 2081. [CrossRef] [PubMed]

2. Graziani, G.; Boi, M.; Bianchi, M. A review on ionic substitutions in hydroxyapatite thin films: Towards complete biomimetism. Coatings 2018, 8, 269. [CrossRef]

3. Duta, L.; Popescu, A.C. Current status on pulsed laser deposition of coatings from animal-origin calcium phosphate sources. Coatings 2019, 9, 335. [CrossRef] 
4. Stan, G.E.; Popescu, A.C.; Mihailescu, I.N.; Marcov, D.A.; Mustata, R.C.; Sima, L.E.; Petrescu, S.M.; Ianculescu, A.; Trusca, R.; Morosanu, C.O. On the bioactivity of adherent bioglass thin films synthesized by magnetron sputtering techniques. Thin Solid Films 2010, 518, 5955-5964. [CrossRef]

5. Campana, V.; Milano, G.; Pagano, E.; Barba, M.; Cicione, C.; Salonna, G.; Lattanzi, W.; Logroscino, G. Bone substitutes in orthopaedic surgery: From basic science to clinical practice. J. Mater. Sci. Mater. Med. 2014, 25, 2445-2461. [CrossRef] [PubMed]

6. LeGeros, R.Z. Hydroxyapatite and Related Materials; CRC Press: Boca Raton, FL, USA, 1994.

7. LeGeros, R.Z. Calcium Phosphates in Oral Biology and Medicine; Karger: Basel, Switzerland, 1991.

8. Ebrahimi, M.; Botelho, M.G.; Dorozhkin, S.V. Biphasic calcium phosphates bioceramics (HA/TCP): Concept, physicochemical properties and the impact of standardization of study protocols in biomaterials research. Mater. Sci. Eng. C 2018, 71, 1293-1312. [CrossRef]

9. Zhou, H.; Lee, J. Nanoscale hydroxyapatite particles for bone tissue engineering. Acta Biomater. 2011, 7 , 2769-2781. [CrossRef]

10. Carrodeguas, R.G.; De Aza, S. $\alpha$-Tricalcium phosphate: Synthesis, properties and biomedical applications. Acta Biomater. 2011, 7, 3536-3546. [CrossRef]

11. Prakasam, M.; Locs, J.; Salma-Ancane, K.; Loca, D.; Largeteau, A.; Berzina-Cimdina, L. Fabrication, properties and applications of dense hydroxyapatite: A review. J. Funct. Biomater. 2015, 6, 1099-1140. [CrossRef]

12. Joo, L.; Ong, D.; Chanm, C.N. Hydroxyapatite and their use as coatings in dental implants: A review. Crit. Rev. Biomed. Eng. 1999, 28, 667-707. [CrossRef]

13. Marques, C.F.; Olhero, S.; Abrantes, J.C.C.; Marote, A.; Ferreira, S.; Vieira, S.I.; Ferreira, J.M.F. Biocompatibility and antimicrobial activity of biphasic calcium phosphate powders doped with metal ions for regenerative medicine. Ceram. Int. 2017, 43, 15719-15728. [CrossRef]

14. Chung, R.-J.; Hsieh, M.-F.; Huang, C.-W.; Perng, L.-H.; Wen, H.-W.; Chin, T.-S. Antimicrobial effects and human gingival biocompatibility of hydroxyapatite sol-gel coatings. J. Biomed. Mater. Res. B 2006, 76, 169-178. [CrossRef] [PubMed]

15. Johnson, C.T.; Garcia, A.J. Scaffold-based anti-infection strategies in bone repair. Ann. Biomed. Eng. 2015, 43, 515-528. [CrossRef] [PubMed]

16. Holloway, J.L. One step solution for fighting bacteria and growing bone. Sci. Transl. Med. 2019, 11, eaaw5326. [CrossRef]

17. Yuan, K.; Chen, K.C.; Chan, Y.J.; Tsai, C.C.; Chen, H.H.; Shih, C.C. Dental implant failure associated with bacterial infection and long-term bisphosphonate usage: A case report. Implant Dent. 2012, 21, 3-7. [CrossRef]

18. Popa, A.C.; Fernandes, H.R.; Necsulescu, M.; Luculescu, C.; Cioangher, M.; Dumitru, V.; Stuart, B.W.; Grant, D.M.; Ferreira, J.M.F.; Stan, G.E. Antibacterial efficiency of alkali-free bio-glasses incorporating ZnO and/or SrO as therapeutic agents. Ceram. Int. 2019, 45, 4368-4380. [CrossRef]

19. Aslam, B.; Wang, W.; Arshad, M.I.; Khurshid, M.; Muzammil, S.; Rasool, M.H.; Nisar, M.A.; Alvi, R.F.; Aslam, M.A.; Qamar, M.U.; et al. Antibiotic resistance: A rundown of a global crisis. Infect. Drug Resist. 2018, 11, 1645-1658. [CrossRef]

20. Badea, M.L.; Iconaru, S.L.; Groza, A.; Chifiriuc, M.C.; Beuran, M.; Predoi, D. Peppermint essential oil-doped hydroxyapatite nanoparticles with antimicrobial properties. Molecules 2019, 24, 2169. [CrossRef]

21. Burt, S. Essential oils: Their antibacterial properties and potential applications in foods-A review. Int. J. Food. Microbiol. 2004, 94, 223-253. [CrossRef]

22. Predoi, D.; Iconaru, S.L.; Buton, N.; Badea, M.L.; Marutescu, L. Antimicrobial activity of new materials based on lavender and basil essential oils and hydroxyapatite. Nanomaterials 2018, 8, 291. [CrossRef]

23. de Carvalho, R.J.; de Souza, G.T.; Honorio, V.G.; de Sousa, J.S.; da Conceiçao, M.L.; Maganani, M.; de Souza, E.L. Comparative inhibitory effects of Thymus vulgaris L. essential oil against Staphylococcus aureus, Listeria monocytogenes and mesophilic starter co-culture in cheese-mimicking models. Food Microbiol. 2015, 52, 59-65. [CrossRef] [PubMed]

24. Bagamboula, C.F.; Uyttendaele, M.; Debevere, J. Antimicrobial effect of spices and herbs on Shigella sonnei and Shigella flexneri. J. Food Prot. 2003, 66, 668-673. [CrossRef] [PubMed]

25. Food and Drug Administration. Part 182 — Substances Generally Recognized a Safe. Subpart A-General Provisions. Sec. 182.10 Species and Other Natural Seasoning and Flavorings. Available online: https: //www.accessdata.fda.gov/scripts/cdrh/cfdocs/cfcfr/cfrsearch.cfm?fr=182.10 (accessed on 27 November 2019). 
26. Ballester-Costa, C.; Sendra, E.; Fernandez-Lopez, J.; Perez-Alvarez, J.A.; Viuda-Martos, M. Chemical composition and in vitro antibacterial properties of essential oils of four Thymus species from organic growth. Ind. Crop. Prod. 2013, 50, 304-311. [CrossRef]

27. Kohiyama, C.Y.; Ribeiro, M.M.Y.; Mossini, S.A.G.; Bando, E.; Bomfim, N.S.; Nerilo, S.B.; Rocha, G.H.O.; Grespan, R.; Mikcha, J.M.G.; Machinski, M., Jr. Antifungal properties and inhibitory effects upon aflatoxin production of Thymus vulgaris L. by Aspergillus flavus Link. Food Chem. 2015, 173, 1006-1010. [CrossRef]

28. Alioui, H.; Bouras, O.; Bollinger, J.C. Toward an efficient antibacterial agent: Zn- and Mg-doped hydroxyapatite nanopowders. J. Environ. Sci. Health Part A-Toxic/Hazard. Subst. Environ. Eng. 2018, 54, 315-327. [CrossRef] [PubMed]

29. Coelho, C.C.; Araujo, R.; Quadros, P.A.; Sousa, S.R.; Monteiro, F.J. Antibacterial bone substitute of hydroxyapatite and magnesium oxide to prevent dental and orthopaedic infections. Mater. Sci. Eng. C 2019, 97, 529-538. [CrossRef]

30. Predoi, D.; Iconaru, S.L.; Predoi, M.V.; Stan, G.E.; Buton, N. Synthesis, characterization, and antimicrobial activity of magnesium-doped hydroxyapatite suspensions. Nanomaterials 2019, 9, 1295. [CrossRef]

31. Zhang, H.; Zhao, C.; Wen, J.; Li, X.; Fu, L. Synthesis and structural characteristics of magnesium and zinc doped hydroxyapatite whiskers. Ceram. Silik. 2017, 61, 244-249. [CrossRef]

32. Landi, E.; Logroscino, G.; Proietti, L.; Tampieri, A.; Sandri, M.; Sprio, S. Biomimetic Mg-substituted hydroxyapatite: From synthesis to in vivo behaviour. J. Mater. Sci. Mater. Med. 2008, 19, 239-247. [CrossRef]

33. Singh, J.; Singh, H.; Batra, U. Magnesium doped hydroxyapatite: Synthesis, characterization and bioactivity evaluation. In Biomaterials Science: Processing, Properties, and Applications V: Ceramic Transactions; Narayan, R., Bose, S., Bandyopadhyay, A., Eds.; Wiley: Hoboken, NJ, USA, 2015; Chapter 15; Volume 254, pp. 161-174.

34. Bernardini, D.; Nasulewic, A.; Mazur, A.; Maier, J.A. Magnesium and microvascular endothelial cells: A role in inflammation and angiogenesis. Front. Biosci. 2005, 10, 1177-1182. [CrossRef]

35. Xu, T.; He, X.; Chen, Z.; He, L.; Lu, M.; Ge, J.; Weng, J.; Mu, Y.; Duan, K. Effect of magnesium particle fraction on osteoinduction of hydroxyapatite sphere-based scaffolds. J. Mater. Chem. B 2019, 7, 5648-5660. [CrossRef] [PubMed]

36. Bigi, A.; Falini, G.; Foresti, E.; Gazzano, M.; Ripamonti, A.; Roveri, N. Magnesium influence on hydroxyapatite crystallization. J. Inorg. Biochem. 1993, 49, 69-78. [CrossRef]

37. Ciobanu, C.S.; Iconaru, S.L.; Massuyeau, F.; Constantin, L.V.; Costescu, A.; Predoi, D. Synthesis, structure, and luminescent properties of europium-doped hydroxyapatite nanocrystalline powders. J. Nanomater. 2012, 2012, 942801. [CrossRef]

38. Predoi, D.; Iconaru, S.L.; Predoi, M.V. Dextran-coated zinc-doped hydroxyapatite for biomedical applications. Polymers 2019, 11, 886. [CrossRef]

39. Predoi, D.; Iconaru, S.L.; Predoi, M.V.; Motelica-Heino, M.; Guegan, R.; Buton, N. Evaluation of antibacterial activity of zinc-doped hydroxyapatite colloids and dispersion stability using ultrasounds. Nanomaterials 2019, 9, 515. [CrossRef]

40. Ciobanu, C.S.; Iconaru, S.L.; Popa, C.L.; Motelica-Heino, M.; Predoi, D. Evaluation of samarium doped hydroxyapatite, ceramics for medical application: Antimicrobial activity. J. Nanomater. 2015, 2015, 849216. [CrossRef]

41. Rodriguez, L.; Matoušek, J. Preparation of $\mathrm{TiO}_{2}$ sol-gel layers on glass. Ceram. Silik. 2003, 47, $28-31$.

42. Popa, A.C.; Stan, G.E.; Husanu, M.A.; Pasuk, I.; Popescu, I.D.; Popescu, A.C.; Mihailescu, I.N. Multi-layer haemocompatible diamond-like carbon coatings obtained by combined radio frequency plasma enhanced chemical vapor deposition and magnetron sputtering. J. Mater. Sci.: Mater. Med. 2013, 24, 2695-2707. [CrossRef]

43. Patel, V.R.; Agrawal, Y.K. Nanosuspension: An approach to enhance solubility of drugs. J. Adv. Pharm. Technol. Res. 2011, 2, 81-87. [CrossRef]

44. Rietveld, H. A profile refinement method for nuclear and magnetic structures. J. Appl. Crystallogr. 1969, 2, 65-71. [CrossRef]

45. Markovic, M.; Fowler, B.O.; Tung, M.S. Preparation and comprehensive characterization of a calcium hydroxyapatite reference material. J. Res. Natl. Inst. Stand. Technol. 2004, 109, 553-568. [CrossRef] [PubMed] 
46. Mocanu, A.C.; Miculescu, M.; Machedon-Pisu, T.; Maidaniuc, A.; Ciocoiu, R.C.; Ionita, M.; Pasuk, I.; Stan, G.E.; Miculescu, F. Internal and external surface features of newly developed porous ceramics with random interconnected 3D channels by a fibrous sacrificial porogen method. Appl. Surf. Sci. 2019, 489, 226-238. [CrossRef]

47. Duta, L.; Mihailescu, N.; Popescu, A.C.; Luculescu, C.R.; Mihailescu, I.N.; Cetin, G.; Gunduz, O.; Oktar, F.N.; Popa, A.C.; Kuncser, A.; et al. Comparative physical, chemical and biological assessment of simple and titanium-doped ovine dentine-derived hydroxyapatite coatings fabricated by pulsed laser deposition. Appl. Surf. Sci. 2017, 413, 129-139. [CrossRef]

48. Stan, G.E.; Marcov, D.A.; Pasuk, I.; Miculescu, F.; Pina, S.; Tulyaganov, D.U.; Ferreira, J.M.F. Bioactive glass thin films depositd by magnetron sputtering technique: The role of working pressure. Appl. Surf. Sci. 2010, 256, 7102-7110. [CrossRef]

49. Can, H.K.; Kavlak, S.; Khosroshahi, S.P.; Guner, A. Preparation, characterization and dynamical properties of dextran-coated iron oxide nanoparticles (DIONPs). Artif. Cell. Nanomed. Biotechnol. 2018, 46, 421-431. [CrossRef]

50. Vettori, M.H.P.B.; Franchetti, S.M.M.; Contiero, J. Structural characterization of a new dextran with a low degree of branching produced by Leuconostoc mesenteroides FT045B dextransucrase. Carbohydr. Polym. 2012, 88, 1440-1444. [CrossRef]

51. Siddiqui, N.N.; Aman, A.; Silipo, A.; Qader, S.A.U.; Molinaro, A. Structural analysis and characterization of dextran produced by wild and mutant strains of Leuconostoc mesenteroides. Carbohydr. Polym. 2014, 99, 331-338. [CrossRef]

52. Mitic, Z.; Nikolic, G.M.; Cakic, M.; Mitic, S.; Nikolic, G.S.; Najman, S. Spectroscopic characterization of cobalt (II) complexes with reduced low-molar dextran derivatives. Acta Fac. Med. Naiss. 2018, 35, 37-48. [CrossRef]

53. Glisic, S.; Nikolic, G.; Cakic, M.; Trutic, N. Spectroscopic study of copper(II) complexes with carboxymethyl dextran and dextran sulfate. Russ. J. Phys. Chem. A 2015, 89, 1254-1262. [CrossRef]

54. Topala, C.M.; Tataru, L.D. ATR-FTIR of thyme and rosemary oils extracted by supercritical carbon dioxide. Rev. Chem. 2016, 67, 842-846.

55. Solan Valderrama, A.C.; Rojas De, G.C. Traceability of active compounds of essential oils in antimicrobial food packaging using a chemometric method by ATR-FTIR. Am. J. Anal. Chem. 2017, 8, 726-741. [CrossRef]

56. Schultz, H.; Quilitzsch, R.; Kruger, H. Rapid evaluation and quantitative analysis of thyme, oregano and chamomile essential oils by ATR-IR and NIR spectroscopy. J. Mol. Struct. 2003, 661-662, 299-306. [CrossRef]

57. Stan, G.E.; Marcov, D.A.; Popa, A.C.; Husanu, M.A. Polymer-like and diamond-like carbon coatings prepared by RF-PECVD for biomedical application. Dig. J. Nanomater. Biostruct. 2010, 5, 705-718.

58. Ibrahim, A.I.O.; Moodley, D.S.; Petrik, L.; Patel, N. Use of antibacterial nanoparticles in Endodontics. S. Afr. Dent. J. 2017, 72, 105-112.

59. Monzavi, A.; Eshraghi, S.; Hashemian, R.; Momen-Heravi, F. In vitro and ex vivo antimicrobial efficacy of nano-MgO in the elimination of endodontic pathogens. Clin. Oral Investig. 2015, 19, 349-356. [CrossRef] [PubMed]

60. Huang, L.; Li, D.-Q.; Lin, Y.-J.; Wei, M.; Evans, D.G.; Duan, X. Controllable preparation of nano-MgO and investigation of its bactericidal properties. J. Inorg. Biochem. 2005, 99, 986-993. [CrossRef]

61. Hammer, K.A.; Carson, C.F.; Riley, T.V. Antimicrobial activity of essential oils and other plant extracts. J. Appl. Microbiol. 1999, 86, 985-990. [CrossRef]

62. Msaada, K.; Salem, N.; Bachrouch, O.; Bousselmi, S.; Tammar, S.; Alfaify, A.; Al Sane, K.; Ben Ammar, W.; Azeiz, S.; Brahim, A.H.; et al. Chemical composition and antioxidant and antimicrobial activities of wormwood (Artemisia absinthium L.) essential oils and phenolics. J. Chem. 2015, 2017, 804658. [CrossRef]

63. Boskovic, M.; Zdravkovic, N.; Ivanovic, J.; Janjic, J.; Djordjevic, J.; Starcevic, M.; Baltic, M.Z. Antimicrobial activity of thyme (Tymus vulgaris) and oregano (Origanum vulgare) essential oils against some food-borne microorganisms. Procedia Food Sci. 2015, 5, 18-21. [CrossRef]

64. Poelstra, K.A.; Barekzi, N.A.; Rediske, A.M.; Felts, A.G.; Slunt, J.B.; Grainger, D.W. Prophylactic treatment of gram-positive and gram-negative abdominal implant infections using locally delivered polyclonal antibodies. J. Biomed. Mater. Res. 2002, 60, 206-215. [CrossRef]

65. Seebach, E.; Kubatzky, K.F. Chronic implant-related bone infections-Can immune modulation be a therapeutic strategy? Front. Immunol. 2019, 10, 1724. [CrossRef]

66. Zimmerli, W.; Sendi, P. Orthopaedic biofilm infections. APMIS 2017, 125, 353-364. [CrossRef] 
67. Zimmerli, W.; Trampuz, A.; Ochsner, P.E. Prosthetic-joint infections. N. Engl. J. Med. 2004, 351, $1645-1654$. [CrossRef]

68. Pan, C.; Zhou, Z.; Yu, X. Coatings as the useful drug delivery system for the prevention of implant-related infections. J. Orthop. Surg. Res. 2018, 13, 220. [CrossRef] [PubMed]

69. Akiyama, T.; Miyamoto, H.; Yonekura, Y.; Tsukamoto, M.; Ando, Y.; Noda, I.; Sonohata, M.; Mawatari, M. Silver oxide containing hydroxyapatite coating has in vivo antibacterial activity in the rat tibia. J. Orthop. Surg. Res. 2013, 31, 1195-1200. [CrossRef] [PubMed]

70. Ueno, M.; Miyamoto, H.; Tsukamoto, M.; Eto, S.; Noda, I.; Shobuike, T.; Kobatake, T.; Sonohata, M.; Mawatari, M. Silver-containing hydroxyapatite coating reduces biofilm formation by methicillin-resistant Staphylococcus aureus in vitro and in vivo. Biomed. Res. Int. 2016, 2016, 8070597. [CrossRef]

71. Lian, X.; Mao, K.; Liu, X.; Wang, X.; Cui, F. In vivo osteogenesis of vancomycin loaded nanohydroxyapatite/collagen/calcium sulfate composite for treating infectious bone defect induced by chronic osteomyelitis. J. Nanomater. 2015, 2015, 261492. [CrossRef]

72. Townsend, L.; Williams, R.L.; Anuforom, O.; Berwick, M.R.; Halstead, F.; Hughes, E.; Stamboulis, A.; Oppenheim, B.; Gough, J.; Grover, L.; et al. Antimicrobial peptide coatings for hydroxyapatite: Electrostatic and covalent attachment of antimicrobial peptides to surfaces. J. R. Soc. Interface 2017, 14, 20160657. [CrossRef]

(C) 2020 by the authors. Licensee MDPI, Basel, Switzerland. This article is an open access article distributed under the terms and conditions of the Creative Commons Attribution (CC BY) license (http://creativecommons.org/licenses/by/4.0/). 